\title{
Infrared Absorption Spectra of Some Cyclic Acetals of Sugars
}

\author{
R. Stuart Tipson, Horace S. Isbell, and James E. Stewart ${ }^{2}$
}

\begin{abstract}
The infrared absorption spectra of twenty-eight 1-methoxyethylidene and isopropylidene acetals of sugars have been recorded and analyzed. The formulas of the compounds were grouped according to structure, and the absorption bands for each group were considered in relation to the bands found for the other structurally related compounds. No bands were found for the unequivocal detection of the 1,3-dioxolane ring attached respectively to an aldopentofuranose or a ketopentofuranose, an aldopentopyranose, an aldohexofuranose, an aldohexopyranose or a ketohexopyranose, a uronic acid salt or lactone, a sugar alcohol, or a sugar keto-acid salt. Regardless of the fine structure of the dioxolane compounds, certain strong bands were observed, but the bands are not easily recognized from an inspection of one or two spectra and are not characteristic of these compounds only.
\end{abstract}

\section{Scope and Purpose of the Project}

For the purpose of discovering correlations that might be of value in structural analysis, this project was primarily undertaken with the object of providing infrared spectrograms of sugar derivatives containing the 1,3-dioxolane ring (I).

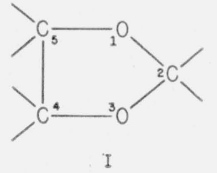

It seemed probable that the vibrations of the dioxolane ring of such compounds would be relatively insensitive to changes in the rest of the molecule; and that it should, accordingly, be possible to identify certain bands in their spectra as being characteristic of this ring. Their spectra have, therefore, been recorded; and the bands have been compiled and studied by statistical and comparative methods.

\section{Compounds Investigated}

In the application of infrared absorption spectra to the determination of structure, it is necessary to have reference spectra for substances of known con-

1 Presented, in part, before the Division of Carbohydrate Chemistry at the 134th Meeting of the American Chemical Society, at Chicago, Ill., on September 9,1958 . Part of this work was supported by the Chemistry Branch of the Office of Naval Research.

2 Present address: Beckman Instruments, Inc., Fullerton, Calif. figuration and conformation. The pyranose ring in simple carbohydrate derivatives is flexible; hence, for some pyranose derivatives, there is much uncertainty concerning the conformation adopted by the ring. In contrast, the conformation of molecules containing fused or bridged rings ${ }^{3}$ is more rigid; and consequently, less uncertainty exists as to the relative steric positions of the atoms and groups within their molecules. For this reason, attention has now been directed to the study of a group of cyclic acetals (of cyclic sugars) having bicyclic and tricyclic structures.

Table 1 gives a list of the compounds, their code numbers $[1]^{4,5}$ and properties, and an index to the spectrograms (the serial number of a compound is the same as the number of its spectrogram). The spectra were measured in the 2 - to $15-\mu$ region $(5,000$ to $667 \mathrm{~cm}^{-1}$; sodium chloride opties) and in the 15 to $40-\mu$ region (667 to $250 \mathrm{~cm}^{-1}$; cesium bromide optics). Inasmuch as a detailed study of all the bands is not possible at present, the spectrograms are given together with a discussion of (a) the structure of the compounds and (b) some of the outstanding features of their spectra.

${ }^{3}$ Fused rings have two adjacent atoms in common, whereas bridged rings have nonadjacent atoms in common.

${ }_{4}$ Figures in brackets indicate the literature references at the end of this paper. The references for table 1 are given at the end of the table.

5 Code numbers are assigned according to a previously published classification system [1], for use with punched-card techniques. 
TABLE 1. Compounds measured and index to spectrograms

\begin{tabular}{|c|c|c|c|c|c|c|c|c|c|}
\hline \multirow{2}{*}{ Code } & \multirow{2}{*}{ Compound } & \multicolumn{4}{|c|}{ Constants reported } & \multicolumn{3}{|c|}{ Constants found } & \multirow[b]{2}{*}{$\begin{array}{l}\text { Spectro- } \\
\text { gram }\end{array}$} \\
\hline & & $\mathrm{mp},{ }^{\circ} \mathrm{C}$ & $\begin{array}{c}\text { Specific } \\
\text { rotation } \\
{[\alpha]_{D}}\end{array}$ & $\begin{array}{l}\text { Rotation } \\
\text { solvent }\end{array}$ & Reference & $\mathrm{mp},{ }^{\circ} \mathrm{C}$ & $\begin{array}{l}\text { Specific } \\
\text { rotation } \\
{[\alpha]_{D}}\end{array}$ & $\begin{array}{l}\text { Rotation } \\
\text { solvent }\end{array}$ & \\
\hline \multicolumn{10}{|c|}{ PYRANOSE DERIVATIVES } \\
\hline \multicolumn{10}{|c|}{ A. 1,2-O-(1-METHOXYETHYLIDENE) ACETALS } \\
\hline $12.22563(3,4,6) 21 \ldots \ldots$ & \multirow{6}{*}{ 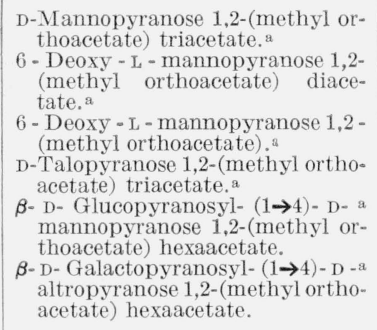 } & 105 & -26.6 & $\mathrm{CHCl}_{3}$ & 1 & 105 to 105.5 & -26.8 & $\mathrm{CHCl}_{3}$ & 1 \\
\hline $12.22563(3,4) 21(6) 80 \ldots$ & & 83 to 84 & +35 & $\mathrm{CHCl}_{3}$ & 2 & 86 to 86.5 & +33.9 & $\mathrm{CHCl}_{3}$ & 2 \\
\hline $10.22563(6) 80$ & & & +16.3 & & 3 & 143 to 144 & +16.0 & $\mathrm{H}_{2} \mathrm{O}$ & 3 \\
\hline $12.24563(3,4,6) 21 \ldots$ & & 91.5 to 92.5 & +3.7 & $\mathrm{CHCl}_{3}$ & 4 & b 77 to 83 & (c) & & 4 \\
\hline $\begin{array}{l}22.215(2,3,4,6) 21^{*}(1-4) .- \\
\quad 22263(3,6) 21\end{array}$ & & 165 to 167 & -13.2 & $\mathrm{CHCl}_{3}$ & 5 & 171 to 172 & -13.0 & $\mathrm{CHCl}_{3}$ & 5 \\
\hline $\begin{array}{l}22.235(2,3,4,6) 21^{*}(1-4) .- \\
\quad 27263(3,6) 21 .\end{array}$ & & 121 to 122 & +25.3 & $?$ & 6 & 121 to 122 & +25.0 & $\mathrm{CHCl}_{3}$ & 6 \\
\hline \multicolumn{10}{|c|}{ B. ISOPROPYLIDENE ACETALS } \\
\hline $10.235(1,2) 61$ & \multirow{5}{*}{$\begin{array}{l}\text { 1,2- } O \text { - Isopropylidene- D- galacto- } \\
\text { pyranosed,e } \\
\text { 1,2:3,4- Di - } O \text { - isopropylidene- } \mathrm{L} \text { - } \\
\text { arabinopyranose. } \\
\text { 1,2:3,4- Di- } O \text { - isopropylidene- D- } \\
\text { galactopyranose6-monoacetate.d } \\
\text { 2,3:4,5- Di- } O \text { - isopropylidene- D- } \\
\text { fructopyranose. } \\
\text { 1,2:4,5- Di- } O \text { - isopropylidene- D- } \\
\text { fructopyranose. } \text { f }^{\text {f }}\end{array}$} & 157 & -10.9 & EtOH & 7 & 156 to 157 & -11.3 & EtOH & 7 \\
\hline $19.135(1,2: 3,4) 61 \ldots$ & & 41.5 to 43 & & & 8 & & & & 8 \\
\hline $19.235(1,2: 3,4) 61(6) 21 \ldots$ & & 108 & -48.1 & $\mathrm{CHCl}_{3}$ & 9 & 110 to 112 & -49.1 & $\mathrm{CHCl}_{3}$ & 9 \\
\hline $19.735(2,3: 4,5) 61 \ldots$ & & 97 & -33.7 & $?$ & 8 & 97 & -33.6 & & 10 \\
\hline $19.735(1,2: 4,5) 61 \ldots$ & & 118 to 119 & -146.6 & $\mathrm{CHCl}_{3}$ & 10 & 117 to 119 & -146.2 & $\mathrm{CHCl}_{3}$ & 11 \\
\hline \multicolumn{10}{|c|}{$\begin{array}{l}\text { FURANOSE DERIVATIVES } \\
\text { ISOPROPYLIDENE ACETALS }\end{array}$} \\
\hline $10.116(1,2) 61 \ldots$ & \multirow{16}{*}{ 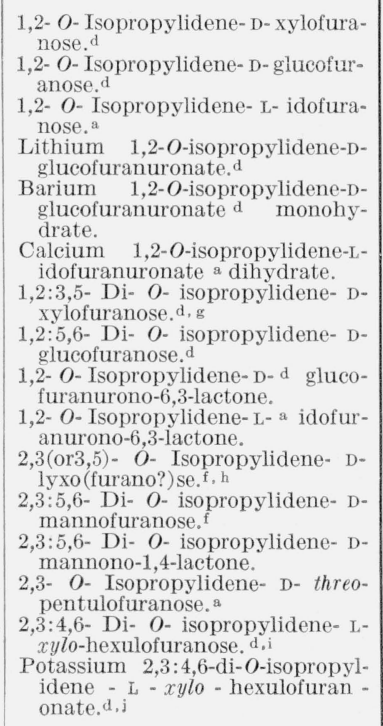 } & 41 to 43 & -17.3 & $0.2 \% \mathrm{HCl}$ & 11,12 & 43 to 45 & -17.5 & $\mathrm{H}_{2} \mathrm{O}$ & 12 \\
\hline $10.216(1,2) 61 \ldots$ & & 161 to 162.5 & -11.8 & $\mathrm{H}_{2} \mathrm{O}$ & 13 & 159 to 161 & -11.8 & $\mathrm{H}_{2} \mathrm{O}$ & 13 \\
\hline $10.256(1,2) 61 \ldots$ & & 113 to 114 & -28.7 & $\mathrm{H}_{2} \mathrm{O}$ & 14,15 & 113 to 115 & -29.0 & $\mathrm{H}_{2} \mathrm{O}$ & 14 \\
\hline $10.216(1,2) 6175 \ldots$ & & dec. & -3.8 & $\mathrm{H}_{2} \mathrm{O}$ & 16 & dec. & -3.8 & $\mathrm{H}_{2} \mathrm{O}$ & 15 \\
\hline $10.216(1,2) 617599$ & & & & & 17 & dec. & -2.9 & $\mathrm{H}_{2} \mathrm{O}$ & 16 \\
\hline $10.256(1,2) 617599 \ldots$ & & $\cdots$ & -11.8 & $\mathrm{H}_{2} \mathrm{O}$ & 18 & dec. & -11.8 & $\mathrm{H}_{2} \mathrm{O}$ & 17 \\
\hline $19.116(1,2: 3,5) 61 \ldots$ & & 44 to 45 & +19.5 & $\mathrm{Me}_{2} \mathrm{CO}$ & 19,20 & 44 to 45 & +19.8 & $\mathrm{Me}_{2} \mathrm{CO}$ & 18 \\
\hline $19.216(1,2: 5,6) 61 \ldots$ & & 110 to 111 & -18.5 & $\mathrm{H}_{2} \mathrm{O}$ & 8,13 & 111 to 113 & -19.7 & $\mathrm{H}_{2} \mathrm{O}$ & 19 \\
\hline $10.216(1,2) 61(6,3) 72 \ldots \ldots$ & & 119 to 120 & +70 & $\mathrm{H}_{2} \mathrm{O}$ & 21 & 118 to 119 & +68.7 & $\mathrm{H}_{2} \mathrm{O}$ & 20 \\
\hline $10.256(1,2) 61(6,3) 72 \ldots$ & & 137 to 138 & +91 & $\mathrm{Me}_{2} \mathrm{CO}$ & 14 & b 134 to 136 & (c) & & 21 \\
\hline $10.126(2,3) ? 61 \ldots$ & & 79 to 80 & +26.0 & $\mathrm{Me}_{2} \mathrm{CO}$ & 20 & 79 to 80 & +26.1 & $\mathrm{Me}_{2} \mathrm{CO}$ & 22 \\
\hline $19.2260(2,3: 5,6) 61 \ldots$ & & 122 & +26.8 & $\mathrm{Me}_{2} \mathrm{CO}$ & 22 & 125 to 126.5 & +25.0 & $\mathrm{Me}_{2} \mathrm{CO}$ & 23 \\
\hline $19.229(2,3: 5,6) 61(1,4) 72 \ldots$ & & 126 & +51 & $\mathrm{CHCl}_{3}$ & 23 & 124 & +50.2 & $\mathrm{CHCl}_{3}$ & 24 \\
\hline $10.626(2,3) 61 \ldots$ & & 70 to 71 & +1.7 & $\mathrm{Me}_{2} \mathrm{CO}$ & 20 & 69 to 70 & (c) & & 25 \\
\hline $19.716(2,3: 4,6) 61 \ldots$ & & 77 to 78 & -18.1 & $\mathrm{Me}_{2} \mathrm{CO}$ & 24 & 78.5 to 80 & -17.0 & $\mathrm{Me}_{2} \mathrm{CO}$ & 26 \\
\hline $19.71675(2,3: 4,6) 61 \ldots$ & & $>290$ & -13.8 & $\mathrm{H}_{2} \mathrm{O}$ & 24 & $>300$, dec. & -14.0 & $\mathrm{H}_{2} \mathrm{O}$ & 27 \\
\hline \multicolumn{10}{|c|}{$\begin{array}{l}\text { ACYCLIC DERIVATIVE } \\
\text { ISOPROPYLIDENE ACETAL }\end{array}$} \\
\hline $19.227(1,2: 5,6) 61 \ldots$ & $\begin{array}{l}\text { 1,2:5,6- Di- } O \text { - isopropylidene- D- } \\
\text { mannitol. }\end{array}$ & 122 & +1.2 & $\mathrm{H}_{2} \mathrm{O}$ & 25 & 115 to 117 & +1.0 & $\mathrm{H}_{2} \mathrm{O}$ & 28 \\
\hline
\end{tabular}

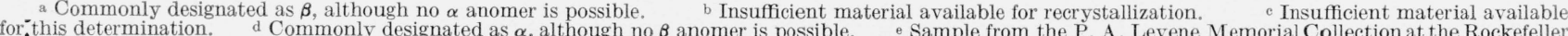

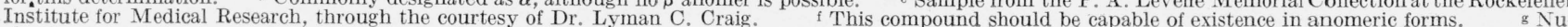

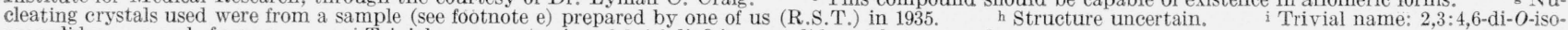
propylid ene- $\alpha$-L-sorbofuranose. $\quad$ i Trivial name: potassium 2,3:4,6-di- $O$-isopropylidene-2-keto- $\alpha$-L-gulonate. 
1. J. K. Dale, J. Am. Chem. Soc. 46, 1046 (1924)

2. W. N. Haworth, E. L. Hirst, and H. Samuels, J. Chem. Soc. 1931, 2861.

3. E. Fischer, M. Bergmann, and A. Rabe, Ber. deut. chem. Ges, 53, $2362(1920)$

4. W. W. Pigman and H. S. Isbell, J. Research NBS 19, 189 (1937) RP1021,

5. H. S. Isbell, BS J. Research 7, 1115 (1931) RP392.

6. H. L. Frush and H. S. Isbell, J. Research NBS 27,413 (1941) RP1429.

7. P. A. Levene and G. M. Meyer, J. Biol. Chem. 64, 473 (1925).

8. E. Fischer, Ber. deut. chem. Ges. 28, 1145 (1895).

9. H Ohle and G. Berend, Ber. deut. chem. Ges. 58, 2585 (1925).

10. D. H. Brauns and H. L. Frush, BS J. Research 6, 449 (1931) RP287.

11. O. Svanberg and K. Sjöberg, Ber. deut. chem. Ges. 56, 863 (1923).

12. W. N. Haworth and C. R. Porter, J. Chem. Soc. 1928, 611

13. E. Fischer and C. Rund, Ber, deut. chem. Ges. 49, 88 (1916).
14. F. Shafizadeh and M. L. Wolfrom, J. Am. Chem. Soc. 77,2568 (1955).

15. A. S. Meyer and T. Reichstein, Helv. Chim. Acta 29, 152 (1946).

16. R. Schaffer and H. S. Isbell, J. Research NBS 56, 191 (1956) RP2667.

17. C. L. Mehltretter, B. H. Alexander, R. L. Mellies, and C. E. Rist, J. Am. Chem. Soc. 73, 2424 (1951)

18. R. Schaffer and H. S. Isbell, J. Am. Chem. Soc. 79, 3867 (1957).

19. P. A. Levene and A. L. Raymond, J. Biol. Chem. 102, 317 (1933).

20. P. A Levene and R. S. Tipson, J Biol, Chem, 115, 731 (1936).

21. L. N. Owen, S. Peat, and W. J. G. Jones, J. Chem. Soc. 1941, 339

22. J. C. Irvine and A. F. Skinner, J. Chem. Soc. 1926, 1089.

22. J. C. Irvine and A. F. Skinner, J. Chem. Soc. 1926, 1089.

23. H. Ohle and G. Berend, Ber. deut. chem. Ges. 58, 2590 (1925).

25. L, von Vargha ,Ber, deut. chem. Ges, 66, 1394 (1933).
As a common structural feature, these compounds have the substituted 1,3-dioxolane ring:

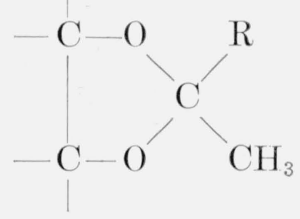

where $\mathrm{R}=\mathrm{OCH}_{3}$ in the 1-methoxyethylidene acetals (methyl orthoacetates), and $\mathrm{R}=\mathrm{CH}_{3}$ in the isopropylidene acetals. All of the compounds have at least one dioxolane ring; and, except for 1,2:5,6-di- $O$ isopropylidene-D-mannitol (compound 28), this ring is fused to either a five- or a six-membered ring.

The precise shape of the dioxolane ring is not known. The bond lengths and bond angles of the atoms comprising the ring are, however, compatible with a planar conformation. The abundance of compounds of this kind having structures explicable by a planar or nearly planar dioxolane ring would tend to support the hypothesis that the ring ordinarily has a planar conformation.

\section{Structures of the Compounds}

\subsection{Methyl Orthoacetates}

The 1-methoxyethylidene acetals or 1,2-(methyl orthoacetate(s)), compounds 1 to 6 , were prepared in the course of investigations on the mechanisms of replacement reactions conducted over the course of many years $[2,3,4]$. They are acetals containing the

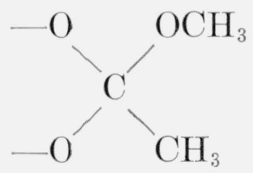

group fused to $\mathrm{C} 1$ and $\mathrm{C} 2$ of a pyranose ring. In both chair conformations, ${ }^{6}$ the cis pair of hydroxyl

\footnotetext{
${ }^{6}$ A discussion of the chair conformations of pyranoid rings is given in a previous
} article [1]. groups at $\mathrm{C} 1$ and $\mathrm{C} 2$ of the parent sugars is equatorial-axial. Spanning them with a planar dioxolane ring would introduce strain. Hence the pyranose ring or the dioxolane ring, or both, would be somewhat distorted. The following depicts the skeletal structure of a possible sofa conformation:

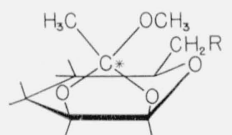

For compounds $1,4,5$, and $6, \mathrm{R}=\mathrm{OAc}$; for compounds 2 and $3, \mathrm{R}=\mathrm{H}$, and the structure is the mirror image of that depicted.

Although the pyranose ring normally assumes a chair conformation, spanning of $\mathrm{C} 1$ and $\mathrm{C} 2$ of a boat form of the pyranose ring with a planar dioxolane ring tends to place $\mathrm{C} 1, \mathrm{C} 2, \mathrm{C} 3$, and the oxygen atom (of the pyranose ring) in a plane at an angle of $120^{\circ}$ to the dioxolane ring. Two conformations of this type seem possible, depending on the positions of $\mathrm{C} 4$ and $\mathrm{C} 5$ of the boat. In one conformation, hereafter designated endo, they are directed toward the dioxolane ring, with $\mathrm{C} 6$ in an axial position; in the other conformation, designated exo, these carbon atoms (C4 and C5) are directed outward from the dioxolane ring, with $\mathrm{C} 6$ in an equatorial position. ${ }^{7}$ The two skeletal structures are depicted in the following formulas:
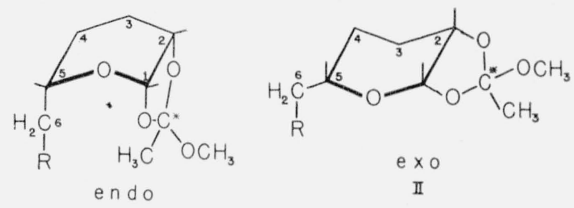

In forming the 1,2-(methyl orthoacetate) from the poly-O-acetylglycosyl halide by the opposite-face mechanism [6], the endo structure would arise by turning the nascent dioxolane ring (in the transition

${ }^{7}$ An endo substituent lies in the $\mathrm{V}$ of a bicyclic structure, whereas an exo substituent lies outside it [5]. 
state) inward toward C6; and the exo structure (II) would arise by turning it outward. The exo form would seem to be the more probable for the methyl orthoacetates, because the overall structure is more nearly planar and there is less crowding of the atoms.

All of the orthoacetates studied have essentially the same ring structures. A summary of the positions of the reference groups in the exo-boat form (II) of each of these methyl orthoacetates is given in table 2. The ester carbon atom (marked with an asterisk) of the orthoacetates is asymmetric; there is no experimental basis for assigning configuration to it, but since the methoxyl group is larger than the methyl group, it would tend to be directed away from the $\mathrm{V}$ of the bicyclic structure.

Decision between the possible conformations indicated must await the outcome of further experimental work.

Isopropylidene derivatives analogous to compounds 1 to 6 (having a methyl group in place of the methoxyl group) seem feasible, but are not known at present. The 1,2-Oisopropylidene-D-galactopyranose considered in the next section is closely related; however, it differs in having the opposite configuration at $\mathrm{C} 1$ and $\mathrm{C} 2$. The 1,2:3,4-di-Oisopropylidene derivatives discussed in the next section are also related to the orthoacetates studied, but they may have a more rigid structure because of the stabilizing effect of the second dioxolane ring.

\subsection{O-Isopropylidene-Pyranose Acetals}

Compound 7 of table 1 has one dioxolane ring fused to a pyranose ring. The latter could have a boat (probably exo) conformation; however, it might have a distorted sofa conformation in which, at C2, C3, and $\mathrm{C} 4$, both exocyclic bonds are approximately quasi instead of being axial-equatorial. The sofa conformation (III) that is equatorially 5 -substituted is depicted.
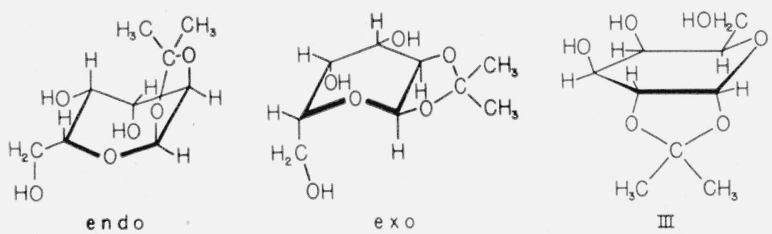

\section{ซ. 1,2-O-Isopropylidene-D-galactopyranose}

Compounds 8 to 10 are isopropylidene acetals which, unlike the orthoacetates, have two dioxolane rings fused, on opposite sides, to a pyranose ring. The presence of two nearly planar dioxolane rings in this position is not compatible with the exo-boat conformation of the pyranose ring most probably present in the orthoacetates (compounds 1 to 6 ). The two pairs of cis hydroxyl groups (at $\mathrm{C} 1$ and $\mathrm{C} 2$, and at $\mathrm{C} 3$ and $\mathrm{C} 4$, for compounds 8 and 9 ) of the parent sugars are each axial-equatorial in both chair-conformations $;^{6}$ and spanning them with a planar dioxolane ring would introduce strains (see IVa). A sofa conformation, in which the pyranose ring or the dioxolane rings (or both) may be somewhat distorted, seems possible. One structure with very little strain is shown in formula $\mathrm{IVb}$.
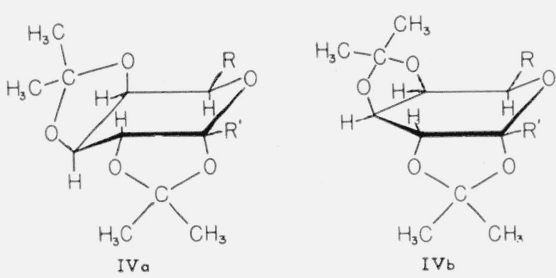

Compounds 8,9 , and 10 presumably have one or the other of the above general structures, with the following substituents.

8. 1,2:3,4-Di- $O$-isopropylidene-L-arabinopyranose, $\mathrm{R}=\mathrm{H} ; \mathrm{R}^{\prime}=\mathrm{H}$.

9. 1,2:3,4-Di-O-isopropylidene-D-galactopyranose monoacetate, $\mathrm{R}=\mathrm{CH}_{2} \mathrm{OAc} ; \mathrm{R}^{\prime}=\mathrm{H}$.

10. $2,3: 4,5$ - $\mathrm{Di}$ - $O$-isopropylidene-D - fructopyranose [1-C-(hydroxymethyl) - 1,2:3,4 - di - $O$-isopropylidene-D-arabinopyranose], $\mathrm{R}=\mathrm{H} ; \mathrm{R}^{\prime}=\mathrm{CH}_{2} \mathrm{OH}$; and the molecule is the mirror image of that depicted.

1,2:4,5-Di- $O$-isopropylidene-D-fructopyranose (compound 11) differs from the four other derivatives in this group in having a spirane structure at $\mathrm{C} 2$, instead of a fused-ring structure. The boat conformation

TABLE 2. Reference groups ${ }^{*}$ on the carbon atoms of the pyranoid ring of the exo-boat conformation (II) of some 1,2-(methyl orthoacetates)

\begin{tabular}{|c|c|c|c|c|c|c|c|c|c|c|}
\hline \multirow{2}{*}{ Compound } & \multicolumn{2}{|c|}{$\mathrm{C} 1$} & \multicolumn{2}{|c|}{$\mathrm{C} 2$} & \multicolumn{2}{|c|}{ C3 } & \multicolumn{2}{|c|}{$\mathrm{C} 4$} & \multicolumn{2}{|c|}{ C5 } \\
\hline & Group & Position b & Group & Position & Group & Position b & Group & Position & Group & Position \\
\hline $\begin{array}{l}1 \\
2 \\
3 \\
5 \\
6\end{array}$ & $\begin{array}{l}\text { (c) } \\
(\mathrm{c}) \\
(\mathrm{c}) \\
(\mathrm{c}) \\
(\mathrm{c}) \\
(\mathrm{c})\end{array}$ & $\begin{array}{l}\mathrm{e} \\
\mathrm{e} \\
\mathrm{e} \\
\mathrm{e} \\
\mathrm{e} \\
\mathrm{e}\end{array}$ & $\begin{array}{l}\text { (c) } \\
\text { (c) } \\
(\mathrm{c}) \\
(\mathrm{c}) \\
(\mathrm{c}) \\
\text { (c) }\end{array}$ & $\begin{array}{l}\mathrm{e} \\
\mathrm{e} \\
\mathrm{e} \\
\mathrm{e} \\
\mathrm{e} \\
\mathrm{e}\end{array}$ & $\begin{array}{l}\text { OAc } \\
\text { OAC } \\
\text { OH } \\
\text { OAc } \\
\text { OAC } \\
\text { OAC }\end{array}$ & $\begin{array}{l}\mathrm{a} \\
\mathrm{a} \\
\mathrm{a} \\
\mathrm{a} \\
\mathrm{a} \\
\mathrm{e}\end{array}$ & $\begin{array}{c}\text { OAc } \\
\text { OAc } \\
\text { OH } \\
\text { OAc } \\
\text { O(AcG)d } \\
\text { O(AcGal) }\end{array}$ & $\begin{array}{l}\mathrm{a} \\
\mathrm{a} \\
\mathrm{a} \\
\mathrm{e} \\
\mathrm{a} \\
\mathrm{a}\end{array}$ & $\begin{array}{l}\mathrm{CH}_{2} \mathrm{OAc} \\
\mathrm{CH}_{3} \\
\mathrm{CH}_{3} \\
\mathrm{CH}_{2} \mathrm{OAc} \\
\mathrm{CH}_{2} \mathrm{OAc} \\
\mathrm{CH}_{2} \mathrm{OAc}\end{array}$ & $\begin{array}{l}e \\
e \\
e \\
e \\
e \\
e\end{array}$ \\
\hline
\end{tabular}

a A reference group is any group, other than hydrogen, attached to a carbon atom of the skeletal structure.

$\mathrm{b}$ The symbols a and $e$ are used to designate axial and equatorial positions, respectively, of the reference groups.

The oxygen atoms of $\mathrm{C} 1$ and $\mathrm{C} 2$ share a 1 -methoxyethylidene grouping.

d (AcG) represents a tetra- $O$-acetyl- $\beta$-D-glucopyranosyl group.

- (AcGal) represents a tetra- $\boldsymbol{O}$-acetyl- $\boldsymbol{\beta}$-D-galactopyranosyl group. 
shown seems plausible; it somewhat resembles the exo form of the methyl orthoacetates (compounds 1 to 6 ), but differs in the position of the fused ring

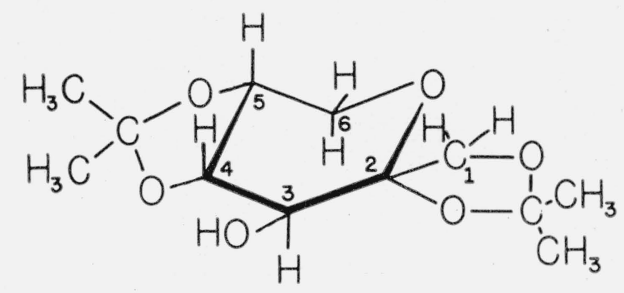

11. $1,2: 4,5$-Di- $O$-isopropylidene-D -fructopyranose

and in having the spirane structure. It may be noted that, whereas the pyranose compounds 1 to 10 cannot exist in anomeric forms, $\alpha$ and $\beta$ anomers of compound 11 should be capable of existence.

\subsection{O-Isopropylidene-Furanose and O-Isopropyl- idene- $\gamma$-lactone Derivatives}

Compounds 12 to 27 have either one or two dioxolane rings fused onto a furanose or a $\gamma$-lactone structure, or both. Because these compounds have 5 -membered rings only, the molecules are more rigid than those having fused dioxolane-pyranose structures. Each ring is substantially planar, and hence only one conformation seems probable. In compounds 12 through 21, carbon atoms 1 and 2 are shared by the rings, and in $22,{ }^{8} 23$, and 24 , carbon atoms 2 and 3 are shared. In each case, the fused rings are inclined at an angle of $120^{\circ}$ to each other.

Compounds 12 to 19 have the following general structure:

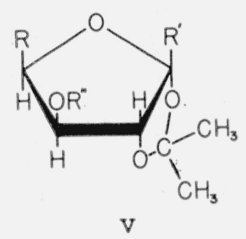

12. 1,2-O-Isopropylidene-D-xylofuranose,

$$
\mathrm{R}=\mathrm{HOCH}_{2}-; \mathrm{R}^{\prime} \text { and } \mathrm{R}^{\prime \prime}=\mathrm{H} \text {. }
$$

13. 1,2-O-Isopropylidene-D-glucofuranose,

$$
\mathrm{R}=\mathrm{HOCH}_{2} \cdot \underset{\mathrm{OH}}{\mathrm{C}} ; \mathrm{R}^{\prime} \text { and } \mathrm{R}^{\prime \prime}=\mathrm{H} .
$$

14. 1,2-O-Isopropylidene-L-idofuranose,

$$
\mathrm{R}=\mathrm{HOCH}_{2} \cdot \mathrm{C}-\mathrm{H}-\mathrm{R}^{\prime} \text { and } \mathrm{R}^{\prime \prime}=\mathrm{H} .
$$

15. Lithium 1,2-O-isopropylidene-D-glucuronate,

$$
\mathrm{R}=\mathrm{LiO}_{2} \mathrm{C} \cdot \stackrel{\mathrm{H}}{\mathrm{OH}} ; \mathrm{R}^{\prime} \text { and } \mathrm{R}^{\prime \prime}=\mathrm{H} \text {. }
$$

\section{$\mathrm{OH}$}

${ }^{8}$ Proof of the structure of this compound will be given in a fortheoming publication.
16. Barium 1,2-O-isopropylidene-D-glucuronate,

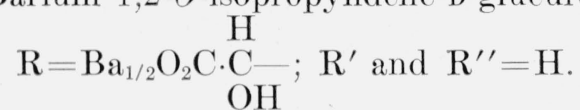

17. Calcium 1,2-O-isopropylidene-L-iduronate,

$$
\mathrm{R}=\mathrm{Ca}_{1 / 2} \mathrm{O}_{2} \mathrm{C} \cdot \mathrm{OH}-\mathrm{C}-\mathrm{R}^{\prime} \text { and } \mathrm{R}^{\prime \prime}=\mathrm{H} \text {. }
$$

18. 1,2:3,5-Di- $O$-isopropylidene-D-xylofuranose,

$$
\mathrm{RR}^{\prime \prime}=\mathrm{H}_{2} \mathrm{CO} \quad \mathrm{C}\left(\mathrm{CH}_{3}\right)_{2} ; \mathrm{R}^{\prime}=\mathrm{H} \text {. }
$$

19. 1,2:5,6-Di- $O$-isopropylidene-D-glucofuranose,

$$
\mathrm{R}=\mathrm{H}_{2} \mathrm{C}-\mathrm{C}-; \mathrm{R}^{\prime} \text { and } \mathrm{R}^{\prime \prime}=\mathrm{H} \text {. }
$$<smiles>CC(C)(O)O</smiles>

The isopropylidene derivatives of D-glucuronolactone and L-iduronolactone (compounds 20 and 21) have three fused, 5-membered rings; the furanose ring occupies a middle position, sharing $\mathrm{C} 1$ and $\mathrm{C} 2$ with the dioxolane ring and $\mathrm{C} 3$ and $\mathrm{C} 4$ with the lactone ring. The dioxolane ring lies on one side of the plane of the middle ring at an angle of $120^{\circ}$; the lactone ring lies on the other side at an angle of $120^{\circ}$, but is not parallel to the dioxolane ring. Compounds 20 and 21 have the following general structure.

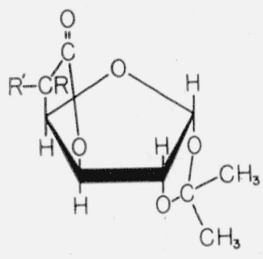

20. 1,2-O-Isopropylidene-D-glucofuranurono-6,3-lactone, $\mathrm{R}=\mathrm{H} ; \mathrm{R}^{\prime}=\mathrm{OH}$.

21. 1,2-O-Isopropylidene-L-idofuranurono-6,3-lactone, $\mathrm{R}=\mathrm{OH} ; \mathrm{R}^{\prime}=\mathrm{H}$.

Compounds $22,{ }^{8} 23$, and 24 have a dioxolane ring fused at $\mathrm{C} 2$ and $\mathrm{C} 3$ of the furanose ring and of the $\gamma$-lactone ring, respectively. It may be noted that, for compounds $22^{8}$ and $23, \alpha$ and $\beta$ anomers should be capable of existence. Compounds $22,{ }^{8} 23$, and 24 have the following general structure.

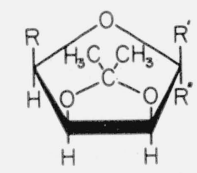

22. 2,3-O-Isopropylidene-D-lyxofuranose, ${ }^{8}$

$\mathrm{R}=\mathrm{HOCH}_{2}-; \mathrm{R}^{\prime}=\mathrm{H}$ and $\mathrm{R}^{\prime \prime}=\mathrm{OH}$

(or vice versa). 
23. 2, 3:5, 6-Di- $O$-isopropylidene-D-mannofuranose,<smiles>[R]CC(C)(OC)OC</smiles>

$\mathrm{R}^{\prime}=\mathrm{H}$ and $\mathrm{R}^{\prime \prime}=\mathrm{OH}$ (or vice versa).

24. 2,3:5,6-Di-O-isopropyliden e-D-mannono-1,4lactone, $\mathrm{R}=\mathrm{H}_{3} \mathrm{C} \quad \mathrm{OCH}_{2} ; \mathrm{R}^{\prime}$<smiles>[R]OC(C)OC</smiles>

The ketose derivatives 25,26 , and 27 have a dioxolane ring fused at $\mathrm{C} 2$ and $\mathrm{C} 3$; but if the compounds are regarded as substituted aldoses, these carbon atoms may be classified as $\mathrm{C} 1$ and $\mathrm{C} 2$ of the furanose ring. Referring back to the skeletal structure $\mathrm{V}$, these compounds have that structure; but, in each case, the molecule is the mirror image of that depicted. The following are the respective substituents:

25. 2,3-O-Isopropylidene-D - threo-pentulofuranose

[1-C-(hydroxymethyl)-1,2-O-isopropylidene-Dthreo-tetrofuranose],

$\mathrm{R}$ and $\mathrm{R}^{\prime \prime}=\mathrm{H} ; \mathrm{R}^{\prime}=\mathrm{CH}_{2} \mathrm{OH}$.

26. $2,3: 4,6$ - Di- $O$-isopropylidene-L-sorbofuranose [1-C-(hydroxymethyl)-1,2:3,5-di- $O$-isopropylidene-L-xylofuranose],

$$
\mathrm{RR}^{\prime \prime}=\mathrm{H}_{2} \mathrm{COCMe}_{2} ; \mathrm{R}^{\prime}=\mathrm{CH}_{2} \mathrm{OH} .
$$

2\%. Potassium 2,3:4,6-di- $O$-isopropylidene-L-xylohexulofuranonate,

$$
\mathrm{RR}^{\prime \prime}=\mathrm{H}_{2} \mathrm{COCMe}_{2} ; \mathrm{R}^{\prime}=\mathrm{COOK} .
$$

\subsection{Substances with a Fused Dioxolane Ring and a Fused $m$-Dioxane Ring}

Compounds 18, 26, and 27 have the following general structure.
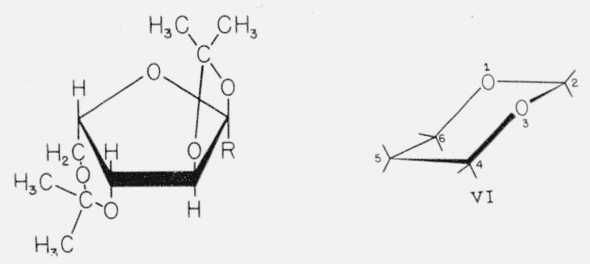

In $\mathbf{2 6}, \mathrm{R}=\mathrm{CH}_{2} \mathrm{OH}$; in $\mathbf{2 \%}, \mathrm{R}=\mathrm{COOK}$; and in 18, $\mathrm{R}=\mathrm{H}$, and the molecule is the mirror image of that depicted. A $m$-dioxane ring (VI) is present in many sugar acetals; hence, determination of absorption which is characteristic of the structure is highly desirable.

\subsection{Substances with "Dangling" Dioxolane Rings}

The isopropylidene group attached to the oxygen atoms at $\mathrm{C} 5$ and $\mathrm{C} 6$ of compounds 19,23 , and 24 forms a dioxolane ring that is free to swing about $\mathrm{C} 4$. Presumably, the position assumed by the group depends on the rest of the molecule, and the infrared spectra might be expected to provide information on this subject. Rings of this character, hereafter called "dangling," should have properties quite different from those of the fused rings which are more rigid.

1,2:5,6-Di- $O$-isopropylidene-D-mannitol, compound 28 , has a dangling dioxolane ring attached by a carbon-carbon bond to each of the carbon atoms of

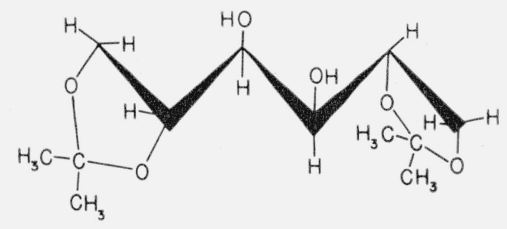

28. 1,2:5,6-Di-O-isopropylidene-D-mannitol

ethylene glycol. Presumably, the spectrum of this substance is typical of spectra of compounds having dangling dioxolane rings, and it should be useful for assisting in the interpretation of the spectra of other compounds containing dangling dioxolane rings. Although, for convenience, the ring can be considered as capable of rotation (dangling), hydrogen bonding and steric factors may restrict the structure to a form in which each dioxolane ring lies in a definite steric position.

\section{Discussion of the Spectra}

Comparison of the spectra of the compounds listed in table 1 , on the basis of the structural features outlined in the preceding sestion, reveals that the absorption bands are not highly characteristic of the type of ring present, and that there are no readily distinguishable bands suitable for the assignment of ring structure or for the study of ring conformation of these compounds. On making a qualitative comparison of any one spectrum with another, it is seen, for example, that in a general way, the spectra of the mono-isopropylidene acetals resemble one another more closely than they do those of the di-isopropylidene acetals, and vice versa, regardless of the particular sugar component or the size (or shape) of the sugar ring.

Although distinctive absorption bands are not apparent for pyranose or furanose, $\gamma$-lactone, 1,3dioxolane, and $m$-dioxane rings, surprisingly large differences are found in the spectra of substances that differ in what might seem to be minor details. These differences can be studied by direct comparison of the spectra for the closely related substances. 
On account of the multiplicity of bands and the lack of highly distinctive ones, detection of absorption characteristic for common structural features requires a statistical examination of the data. For this treatment, the compounds were classified according to their structural features, and the locations of the absorption bands were compiled.

The method used for making comparisons is not conventional, but it seems suitable for the study of groups of related compounds. The distribution of the absorption bands for each group of related compounds was determined for the 2 - to $15 \mu$ - $(5,000$ to $667 \mathrm{~cm}^{-1}$ ) range. First, the number of compounds showing one or more bands (or shoulders) in each wavelength increment of $0.1 \mu$ was counted, and the percentage of such compounds was calculated. This percentage was then plotted against the wavelength, to give the black regions of the plots in figure 1 . Only one region $(3.3$ to $3.4 \mu$ ) immediately revealed. absorption by all of the compounds. Next, those groups of adjacent regions which seemed likely to encompass 100 percent of the compounds were noted and further examined; the results are given in the crosshatched regions of the plots in figure 1.

Because frequency is directly proportional to energy, use of wavenumbers in correlations of the kind sought is preferable to use of wavelength. On the other hand, the recordings (of infrared spectra) produced by the instruments we used are linear in wavelength, and readings from these charts must initially be made in terms of wavelength. Plots of the kind shown in figure 1 (which use $0.1-\mu$ increments in wavelength) are compact, convenient, and reasonably satisfactory for use in analyzing a limited range.

However, for such plots (linear in wavelength), the bands appear crowded at low wavelengths (high frequencies) and become progressively less crowded as the wavelength increases (that is, as the frequency decreases). The $0.1-\mu$ increments from 2.40 to $2.50 \mu$, 9.90 to $10.00 \mu$, and 39.90 to $40.00 \mu$ correspond to decrements of 167,10 , and $0.6 \mathrm{~cm}^{-1}$, respectively.

From the practical standpoint, in making intercomparisons, too much spreading out of bands is just as inconvenient as too much crowding of bane's in such plots. Consequently, for the 10 - to $40-\mu$ range, all wavelengths were converted to wavenumbers; and, in the analysis, decrements of $10 \mathrm{~cm}^{-1}$ in wavenumber were employed. The resulting plots are not reproduced here.

Ultimately, comparisons will be made by use of the classification system described previously [1] using this statistical treatment. The present comparisons are, however, based largely on the structural features characteristic of this relatively limited group of compounds. The compounds were studied in the groups outlined in table 3 . By making comparisons for groups of related compounds that differed in various ways, the manner in which the absorption of the various compounds differed on the average was ascertained. Utilization of averages (instead of the individual absorptions) overcomes, at least in part, the "irregularities" found when the spectra of individual compounds are compared. A few comparisons are given here; others will be deferred for inclusion in a study of a wide variety of carbohydrate derivatives.

TABLE 3. Structural groups studied ${ }^{\mathrm{a}}$

\begin{tabular}{|c|c|c|}
\hline Group & Structural feature & $\begin{array}{l}\text { Compounds (numbers) in } \\
\text { group }\end{array}$ \\
\hline $\begin{array}{l}1 \\
2 \\
3 \\
4 \\
5 \\
6\end{array}$ & $\begin{array}{l}\text { O-Acetyl }(\mathrm{C}=\mathrm{O}) \\
\text { Carboxyl, ionized }\left(\mathrm{COO}^{-}\right) \\
\text {1,3-Dioxolane ring } \\
\text { Hydrate- } \\
\text { Hydroxyl group } \\
\text { Lactone }(\mathrm{C}=\mathrm{O})\end{array}$ & $\begin{array}{l}1,2,4 \text { to } 6,9 \\
15 \text { to } 17,27 \\
1 \text { to } 28 \\
16,17 \\
3,7,10 \text { to } 17,19 \text { to } 23,25,26,28 \\
20,21,24\end{array}$ \\
\hline $\begin{array}{l}7 \\
8\end{array}$ & $\begin{array}{l}\text { altro configuration } \\
\text { arabino configuration (ketopyra- }\end{array}$ & $\begin{array}{l}6 \\
10,11\end{array}$ \\
\hline 9 & $\begin{array}{l}\text { nose), } \\
\text { arabeno; galacto configuration (al- } \\
\text { dopyranose). }\end{array}$ & $8 ; 6,7,9$ \\
\hline 10 & Barium salt & 16 \\
\hline 11 & $\begin{array}{l}\text { Calcium sa } \\
m \text {-Dioxane }\end{array}$ & $\begin{array}{l}17 \\
18,26,27\end{array}$ \\
\hline 13 & $\begin{array}{l}m \text {-Dioxane rin } \\
\text { Furanose ring }\end{array}$ & 12 to 23,25 to 27 \\
\hline 14 & threo; xylo; gluco configuration & $\begin{array}{l}25 ; 12,18,26,27 ; 5,13,15,16, \\
19,20\end{array}$ \\
\hline 15 & Glycoside ( $\beta$-pyranoside) & \\
\hline 16 & Hydroxyl group (glycosidic) & $22(?), 23$ \\
\hline 18 & $\begin{array}{l}\text { Hydroxyl group (primary) } \\
\text { Hydroxyl group (secondary) }\end{array}$ & $\begin{array}{l}7,10,12 \text { to } 14,22(?), 25,26 \\
3,7,11 \text { to } 17,19 \text { to } 21,22(?),\end{array}$ \\
\hline 19 & ido configuration & $\begin{array}{c}25,28 \\
14,17,21\end{array}$ \\
\hline 20 & $1,2-O$-Isopropylidene acetal & 7 to 21,25 to 28 \\
\hline 21 & 2,3-O-Isopropylidene & $22(?), 23,24$ \\
\hline 22 & $\begin{array}{l}5,6 \text { - } O \text {-Isopropylidene acetal ("dan- } \\
\text { gle") }\end{array}$ & $19,23,24,28$ \\
\hline 23 & Lithium salt ... & \\
\hline $\begin{array}{l}24 \\
25\end{array}$ & lyxo: manno configuration & $22 ; 1$ to $3,5,23,24,28$ \\
\hline 25 & $\begin{array}{l}\text { Methoxyl group or methyl ortho- } \\
\text { acetate }\end{array}$ & 1 to 6 \\
\hline 26 & 5- $C$-Methyl (6-Deoxy) group_- & 2,3 \\
\hline $\begin{array}{l}27 \\
28\end{array}$ & Potassi & \\
\hline $\begin{array}{l}28 \\
29\end{array}$ & $\begin{array}{l}\text { Pyranose ring } \\
\text { True } \alpha \text {-Dyranose or } \beta \text {-pyranose }\end{array}$ & 1 to 11 \\
\hline $\begin{array}{l}29 \\
30\end{array}$ & $\begin{array}{l}\text { True } \alpha \text {-pyranose or } \beta \text {-pyranose- } \\
\text { Pyranose (boat conformation?) }\end{array}$ & $\begin{array}{l}5,6,11 \\
1 \text { to } 6,1\end{array}$ \\
\hline 31 & Pyranose (chair conformation?) & 7 to 10 \\
\hline 32 & Sugar ring & 1 to 23,25 to 2 \\
\hline $\begin{array}{l}33 \\
34\end{array}$ & $\begin{array}{l}\text { talo configuration } \\
\text { Three fused rings }\end{array}$ & $\begin{array}{l}4 \\
8 \text { to } 10,18,20,21,26,27\end{array}$ \\
\hline
\end{tabular}

a The bands found for the various compounds will be considered further in publications dealing with specific structural features.

\subsection{Absorption Bands Possibly Attributable to the Dioxolane Ring}

In 1949, Boekelheide and co-workers [7] reported infrared spectra for the 2-amyl-2-methyl and 2-hexyl derivatives of 1,3-dioxolane-4-methanol. In 1950, Kuhn [8] recorded the spectra (in the range 8 to $15 \mu$ ) of 1,2-O-isopropylidene-D-glucofuranose and its 5,6$O$-isopropylidene acetal (along with those of 77 other carbohydrate derivatives), but made no attempt to analyze these particular spectra. In the following year, Smith and Anderson [9] made a study of the infrared spectra of several 1,3-dioxolane derivatives [10], and decided that it is "likely that the presence of a peak at $9.6 \mu$ indicates the presence of a dioxolane ring." However, it remained for Bergmann and Pinchas [11] to conduct a detailed study of the infrared spectra of 18 compounds having the 1,3-dioxolane ring, and to make definite correlations; their data have also been interpreted by Barker, Bourne, and Whiffen [12]. Tschamler and Leutner [13] later observed that compounds containing the 1,3-diox- 

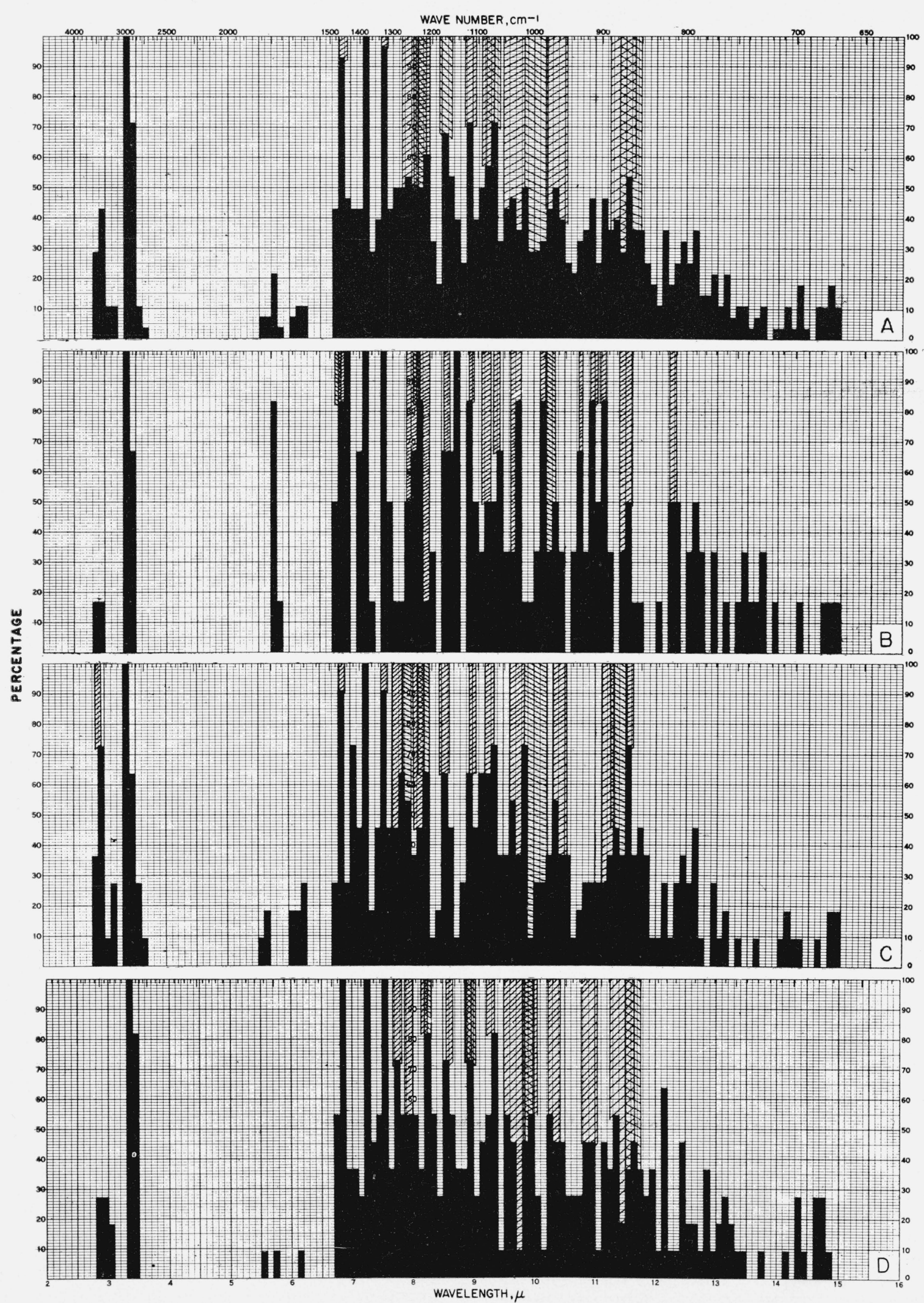

Figure 1. Percentage of the acetals which showed infrared absorption at the various regions of the infrared spectrum (2 to $15 \mu$ ). $\mathbf{A}$,All of the 28 acetals; $\mathbf{B}$, the six methyl orthoacetates; $\mathbf{C}$, the eleven mono- $O$-isopropylidene acetals; $\mathbf{Y}$, the eleven di- $O$-isopropylidene acetals. 
TABLE 4. Absorption bands formerly assigned to the 1,3-dioxolane ring

\begin{tabular}{|c|c|c|c|c|}
\hline \multirow{2}{*}{ Assigned by } & \multicolumn{4}{|c|}{ Wavenumber $\left(\mathrm{cm}^{-1}\right)$ of spectral range of absorption bands } \\
\hline & A & B & $\mathrm{C}$ & $\mathrm{D}$ \\
\hline $\begin{array}{l}\text { Smith and Anderson }[1] \\
\text { Bergmann \& Pinchas tables [2] } \\
\text { Bergmann \& Pinchas text [2] } \\
\text { Barker and co-workers [3] } \\
\text { Tschamler and Leutner [4] }[4 .\end{array}$ & $\begin{array}{r}1190 \text { to } 1151 \\
1190 \text { to } 1158 \\
1173 \text { to } 1151 \\
\text { double } \\
1160\end{array}$ & $\begin{array}{l}1151 \text { to } 1123 \\
1143 \text { to } 1124 \\
1151 \text { to } 1132 \\
\text { vetween } \\
\text { d } 1120\end{array}$ & $\begin{array}{r}1105 \text { to } 1077 \\
1098 \text { to } 1063 \\
1105 \text { to } 1077 \\
\text { double } \\
1110\end{array}$ & $\begin{array}{l}1042 \\
1053 \text { to } 1038 \\
1056 \text { to } 1038 \\
1053 \text { to } 1038 \\
\text { between } \\
\text { d } 1050\end{array}$ \\
\hline
\end{tabular}

References

1. L. I. Smith and R. H. Anderson, J. Org. Chem, 16, 972 (1951)

2. E. D. Bergmann and S. Pinchas, Rec. trav. chim. $\boldsymbol{7 1}_{1}, 161(1952)$

3. S. A. Barker, E. J. Bourne, and D. H. Whiffen, Methods of biochemical analysis, vol. 3, p. 219 (Interscience Publishers, Inc., New York, N.Y., 1956).

4. H. Tschamler and R. Leutner, Monatsh. 83, $1502(1952)$.

olane ring generally show four recognizable absorption bands. Table 4 gives a résumé of the assignments of the prior workers.

Our results are in fair agreement with the figures in the tables of Bergmann and Pinchas [11]: (a) Twelve of the compounds in the present study fail to show a band (B) in the 1151- to $1123-\mathrm{cm}^{-1}$ $(8.80 \pm 0.11 \mu)$ region. However, Bergmann and Pinchas found that the exact location of this band depends more upon the alcoholic than upon the carbonylic residue of the acetal; in possible agreement with this conclusion, a band $\left(\mathrm{B}^{\prime}\right)$ is observed at 1126 to $1104 \mathrm{~cm}^{-1}(8.97 \pm 0.09 \mu)$ for our compounds. (b) Two of our compounds show no band (C) in the 1105 - to $1077-\mathrm{cm}^{-1}(9.17 \pm 0.12 \mu)$ region. (c) Eight of our compounds fail to show a band (D) in the 1053 - to $1038-\mathrm{cm}^{-1}(9.57 \pm 0.07 \mu)$ region.

However, all of our compounds show one or more bands or shoulders in the (A) 1181- to $1153-\mathrm{cm}^{-1}$ $(8.57 \pm 0.10 \mu), \quad\left(B^{\prime}\right) \quad 1126-$ to $1104-\mathrm{cm}^{-1}(8.97 \pm$ $0.09 \mu)$, and $\left(\mathrm{C}^{\prime}\right) 1093$ - to $1070-\mathrm{cm}^{-1}(9.25 \pm 0.10 \mu)$ regions. Except for the spectra of $1,2-O$-isopropylidene- and 1,2:3,5-di- $O$-isopropylidene-D-xylofuranose (compounds 12 and 18), all the spectra show at least one strong band $\left(\mathrm{D}^{\prime}\right)$ at 1055 to $1029 \mathrm{~cm}^{-1}$ $(9.60 \pm 0.12 \mu)$; for the two exceptions, there is a strong band at $1015 \mathrm{~cm}^{-1}(9.85 \mu)$. This characteristic of the D-xylose derivatives is under further study; the spectra of the anomers and glycosides of D-xylose are known to be exceptional [12]. These four bands $\left(\mathrm{A}, \mathrm{B}^{\prime}, \mathrm{C}^{\prime}\right.$, and $\left.\mathrm{D}^{\prime}\right)$ seem to be the most important, but they are not particularly striking inasmuch as they appear in a rather crowded part of the spectrum.

Each substance has an individualistic spectrum useful for identification purposes, but extensive generalization requires great caution. Since many unsubstituted and substituted sugars (and other organic compounds) also show absorption in 2,3 , or even all 4 of the above regions, allocation and interpretation of these bands will be reserved for a more comprehensive study (on a much larger group of sugar derivatives) to be conducted in the same manner.

Many comparisons of limited scope can be made. For example, the spectrum of 1,2:4,5-di-O-isopropylidene-D-fructose (compound 11), a spiro-dioxolane derivative, differs radically from that of its isomer (compound 10) and displays 17 of the 19 bands recorded [14], in the range 2941 to $763 \mathrm{~cm}^{-1}$, for cyclohexane-1,2-di(spiro- $2^{\prime}-1^{\prime}, 3^{\prime}$-dioxolane). In addition to these, it shows 26 other bands in the range 3472 to $726 \mathrm{~cm}^{-1}$.

\subsection{O'her Absorption Bands}

The 28 compounds can be divided into three groups: the methyl orthoacetates, the mono-isopropylidene acetals, and the di-isopropylidene acetals. Bands shown by all the members of each of these groups are given in the crosshatched regions of figure 1 (B, C, and D) and in table 5. It is noted that, in certain regions, more than one interpretation of the data is possible.

Bands shown by all of the compounds in table 1 are shown in the crosshatched regions of figure 1 (A) and in table 5. Selection of one of the alternative ranges exhibited by a subgroup could often be made by intercomparing the ranges for all three subgroups. (Even so, more than one interpretation of ranges for band locations was found possible in certain regions of the spectrum.)

In addition to those mentioned in the preceding section, the following are some of the bands shown by all of the compounds, with possible assignments given in parentheses: 3012 to $2967 \mathrm{~cm}^{-1}$, i.e., 3.32 to $3.37 \mu$ (C-H stretching); 1468 to $1439 \mathrm{~cm}^{-1}$, i.e., 6.81 to $6.95 \mu$ (or 1466 to $1437 \mathrm{~cm}^{-1}$, i.e., 6.82 to $6.96 \mu$ ), and 1333 to $1312 \mathrm{~cm}^{-1}$, i.e., 7.50 to $7.62 \mu$ (C-H bending); 1391 to $1379 \mathrm{~cm}^{-1}$, i.e., 7.19 to $7.25 \mu$ (or 1385 to $1372 \mathrm{~cm}^{-1}$, i.e., 7.22 to $7.29 \mu$ ), often as a doublet (possibly - $\mathrm{CF}_{3}$ deformation, but these bands are shown by many unsubstituted sugars); 1272 to $1236 \mathrm{~cm}^{-1}$, i.e., 7.86 to $8.09 \mu$ (C-O), and 1244 to $1212 \mathrm{~cm}^{-1}$, i.e., 8.04 to $8.25 \mu$, or 1232 to $1205 \mathrm{~cm}^{-1}$, i.e., 8.12 to $8.30 \mu$ (C-O stretching); and 889 to $858 \mathrm{~cm}^{-1}$, i.e., 11.25 to $11.66 \mu$, or 877 to $850 \mathrm{~cm}^{-1}$, i.e., 11.40 to $11.76 \mu$ (1,3-dioxolane ring?). Other bands, which may possibly be correlatable with one or other of these features, were noted at 981.4 to $948.8 \mathrm{~cm}^{-1}, 824.4$ to $793.0 \mathrm{~cm}^{-1}$, and 540.5 to $507.6 \mathrm{~cm}^{-1}$. Some other possibilities noted encompass broader ranges of wavenumber and show overlapping. (They are mentioned in case some of them should prove to be significant, but 


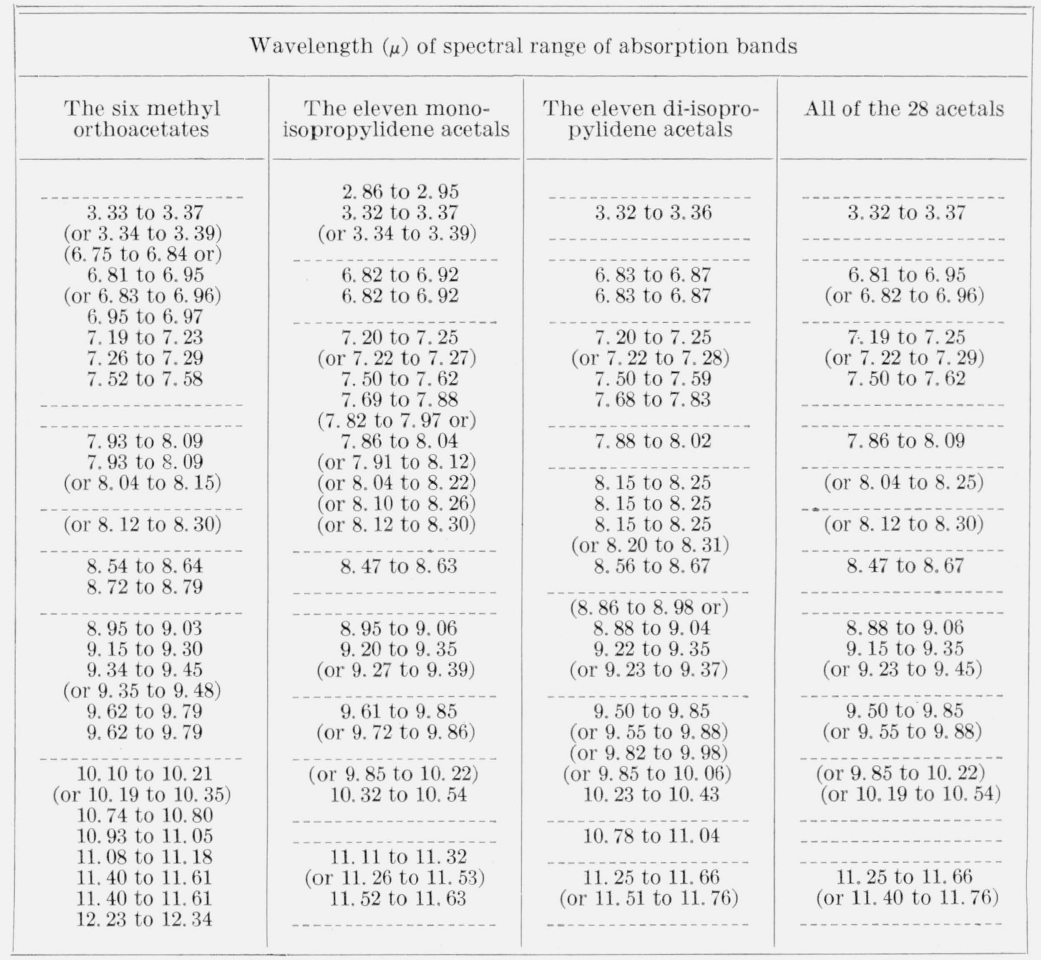

urther work will be needed in order to test this point.) These ranges are: 664.5 to $612.4 \mathrm{~cm}^{-1}$; 580.4 to $524.9 \mathrm{~cm}^{-1} ; 555.6$ to $518.1 \mathrm{~cm}^{-1} ; 532.8$ to $493.8 \mathrm{~cm}^{-1} ; 530.8$ to $487.1 \mathrm{~cm}^{-1} ; 436.7$ to 376.7 $\mathrm{cm}^{-1} ; 428.3$ to $365.6 \mathrm{~cm}^{-1}$. 418.4 to $363.0 \mathrm{~cm}^{-1}$; 410.2 to $349.4 \mathrm{~cm}^{-1}$; and 370.1 to $319.0 \mathrm{~cm}^{-1}$.

The following absorption bands were shown only by compounds (in this study) having the structural features mentioned (groups 1, 2, and 4 to 6 of table $3)$; the wavelengths in microns and the possible assignments are given in parentheses. The acetates showed a band at 1748 to $1739 \mathrm{~cm}^{-1}$ (5.72 to $5.75 \mu$; acetate $\mathrm{C}=\mathrm{O}$ stretching) and at 607.9 to $598.1 \mathrm{~cm}^{-1}$ (16.45 to $16.72 \mu$; acetate deformation). Those compounds having a hydroxyl group and an ionized carboxyl group showed bands at 3145 to $3125 \mathrm{~cm}^{-1}$ (3.18 to $3.20 \mu$; $-\mathrm{OH}$ modified by $\mathrm{C}=\mathrm{O}$ ), at 2786 to $2732 \mathrm{~cm}^{-1}(3.59$ to $3.66 \mu$; $-\mathrm{OH}$ modified by $\mathrm{C}=\mathrm{O})$, and at 1637 to $1600 \mathrm{~cm}^{-1}$ (6.11 to $\left.6.25 \mu ;-\mathrm{COO}^{-}\right)$. The hydrates showed a strong shoulder at $1645 \mathrm{~cm}^{-1}$ $(6.08 \mu$; water of crystallization) and a band at 706.2 to $703.7 \mathrm{~cm}^{-1}$. All of the compounds having one or more free hydroxyl groups showed a band at 3472 to $3279 \mathrm{~cm}^{-1}$ (2.88 to $3.05 \mu$; associated alchoholic $\mathrm{O}-\mathrm{H}$, stretching frequency). Compounds 10 and 28 showed a band at 3289 to $3279 \mathrm{~cm}^{-1}(3.04$ to $3.05 \mu$; H-bonding ?). The lactones showed a band at 1789 to $1764 \mathrm{~cm}^{-1}(5.59$ to $5.67 \mu ; \mathrm{C}=\mathrm{O}$ stretching frequency).

All of the spectra were also studied in regard to the 28 other features listed alphabetically as groups 7 to 34 of table 3 . Those compounds having a $m$-dioxane ring showed a band at 310.3 to 307.7 $\mathrm{cm}^{-1}$. The $\beta$-glycopyranosides showed bands at 967.1 to $966.2 \mathrm{~cm}^{-1}, 811.0$ to $810.4 \mathrm{~cm}^{-1}, 646.0$ to $644.8 \mathrm{~cm}^{-1}$, and 475.1 to $470.6 \mathrm{~cm}^{-1}$. Those compounds having a free hydroxyl group at carbon atom 1 showed a band at 893.7 to $892.1 \mathrm{~cm}^{-1}$ and at 683.1 to $680.7 \mathrm{~cm}^{-1}$. The isopropylidene acetals showed a band at 859.1 to $833.3 \mathrm{~cm}^{-1}$. Those compounds having a sugar ring (including compound 24) showed one or more bands at 914.1 to $884.2 \mathrm{~cm}^{-1}$. (Other possible interpretations are: 900.9 to 878.7 $\mathrm{cm}^{-1}$, or 900.1 to $877.2 \mathrm{~cm}^{-1}$, or 896.9 to $867.3 \mathrm{~cm}^{-1}$, or 892.1 to $861.3 \mathrm{~cm}^{-1}$.) They also showed bands at 653.6 to $611.6 \mathrm{~cm}^{-1}$ and at 591.7 to $544 \mathrm{~cm}^{-1}$. Other possible ranges (which, because of the broader range or the overlapping, may not be significant) are: 639.0 to $578.0 \mathrm{~cm}^{-1} ; 584.8$ to $540.5 \mathrm{~cm}^{-1}$; and 580.4 to $533.3 \mathrm{~cm}^{-1}$. Further work may throw light on the significance of these bands.

From a study of the infrared absorption spectra of sugars and their derivatives capable of existence in anomeric forms (namely, of compounds in which the hydroxyl group of the hemiacetal carbon atom is, for example, free, acetylated, or involved in glycosidic union), Barker and co-workers $[15,16]$ were able to recognize certain absorption bands which were considered to be characteristic of the $\alpha$ and $\beta$ anomers, respectively, of the pyranoid forms. In the present study, the only pyranoid compounds capable of existence as $\alpha$ and $\beta$ anomers are compounds 5,6 , and 11 (which are, respectively, a $\beta$-D-glucoside, a $\beta$-D-galactoside, and a D-fructopyranose derivative), and they show bands fitting the assignments called types 1,2 , and 3 by Barker and 
co-workers. The other pyranoid derivatives, which cannot exist in anomeric forms, show many of the bands in question; but, as might be expected, these do not fit the structural correlations.

Similarly, of the furanoid derivatives, only compound 23 (and possibly ${ }^{8} 22$ ) is capable of existence in anomeric forms, and it shows bands fitting the tentative assignments (for furanoid sugars) called types A, C, and D by Barker and Stephens [17]. The other compounds show many of these bands, but they do not fit the structural correlations.

\section{Experimental Procedures}

\subsection{Preparation and Purification of the Compounds}

The compounds listed in table 1 were prepared by the methods given in the references cited. For compound 4 , the few milligrams of the material remaining from the original preparation of Pigman and Isbell [3] had a melting point somewhat low, but it was apparently in good condition; because of the lack of material for recrystallization, its infrared absorption spectrum (2 to $15 \mu)$ was determined directly, and this showed the presence of a small proportion of free hydroxyl group (band at 3484 $\left.\mathrm{cm}^{-1} ; 2.87 \mu\right)$. For compounds 21 and 25 , the melting points were satisfactory, but insufficient material remained for checking their optical rotations. With these exceptions, each substance was recrystallized or otherwise purified until further treatment caused no change in its melting point or optical rotation. In most cases, these values then agreed with those found in the literature; but where a higher melting point is now given, it is believed that the new values reported in table 1 are correct.

As regards the preparation of compound 12 , by the acid hydrolysis of compound 18, a survey of the literature showed that use of 0.16 percent hydrochloric acid [18, 19], 0.2 percent hydrochloric acid $[20,21], 0.04 N$ sulfuric acid [22], and $0.2 N$ sulfuric acid [23] had been recommended; the last concentration cited may be a misprint. Accordingly, a solution of compound $18(10 \mathrm{~g})$ in $250 \mathrm{ml}$ of $0.05 \mathrm{~N}$ sulfuric acid was kept at room temperature for 2 hours. The acid was then neutralized by adding barium carbonate $(5 \mathrm{~g})$ and shaking until neutral to Congo Red. The suspension was filtered through a layer of Celite plus barium carbonate, and the clear, colorless filtrate was added to barium carbonate $(1 \mathrm{~g})$ and evaporated to dryness under diminished pressure at $30^{\circ}$ (bath temp.). The mixture of sirup plus solid was extracted with acetone and filtered, and the filtrate was dried with anhydrous sodium sulfate, filtered, and evaporated to dryness under diminished pressure. The resulting sirup was distilled (bp $112^{\circ}$ to $114^{\circ} \mathrm{C}$ at $0.06 \mathrm{~mm}$ ), affording an almost quantitative yield of a colorless, viscous sirup which completely crystallized spontaneously. Although previous workers $[18,23]$ have stated that the compound cannot be recrystallized from organic solvents, it may readily be recrystallized from ether $(2$ vols.) plus heptane $(0.2$ vol. $)$ on standing in the freezing compartment of the refrigerator.

\subsection{Preparation of the Pellets}

Samples for spectrophotometric study were prepared in the solid phase, as pellets of the crystalline compound suspended in an alkali-metal halide. The pellets were $9.5 \mathrm{~mm}$ in diameter and weighed approximately $100 \mathrm{mg}$; the weight of sample per 100 $\mathrm{mg}$ of potassium chloride (for the $2-$ to $15-\mu$ region) or per $100 \mathrm{mg}$ of potassium iodide (for the 15- to $40-\mu$ region) is shown in table 6 . The accuracy of weighing was not high $( \pm 0.1 \mathrm{mg}$ per $\mathrm{mg}$ of sample), but this was relatively unimportant in view of other factors to be discussed. No special precautions, beyond working under an infrared lamp and storage in a vacuum desiccator, were taken for drying the powder, which was hand-ground in a Mullite mortar. The pellets were pressed in a simple, nonevacuable, three-piece die, consisting of a cvlindrical body and two plungers $(9.5 \mathrm{~mm}$ in diameter), similar to one described by Anderson and Woodall [24]. A machine-shop vise was used for applying pressure (estimated to be 20 tons/in. ${ }^{2}$ for pellets of this diameter). Satisfactory pellets were obtained without evacuation. It should be noted that there may have been a slight variation in pellet thickness from pellet to pellet.

TABLE 6. Conditions for recording the spectra

\begin{tabular}{|c|c|c|c|c|c|}
\hline \multirow{2}{*}{$\begin{array}{c}\begin{array}{c}\text { Com- } \\
\text { pound }\end{array} \\
\\
\\
\\
1 \\
2 \\
3 \\
4 \\
5\end{array}$} & \multirow{2}{*}{$\begin{array}{c}\text { Molecular } \\
\text { weight }\end{array}$} & \multicolumn{2}{|c|}{$\begin{array}{c}\text { Concentration for } 2-\text { to } \\
15-\mu \text { range }\end{array}$} & \multicolumn{2}{|c|}{$\begin{array}{l}\text { Concentration for } 15- \\
\text { to } 40-\mu \text { range }\end{array}$} \\
\hline & & $\begin{array}{c}\mathrm{mg} / 100 \mathrm{mg} \\
\mathrm{KCl} \\
0.4 \\
.4 \\
.4 \\
.4 \\
.4\end{array}$ & $\begin{array}{c}\text { mole/kg of } \\
\text { mixture } \\
0.01_{1} \\
.01_{3} \\
.01_{8} \\
.01_{1} \\
.006\end{array}$ & \begin{tabular}{c}
$m g / 100 m g$ \\
$K I$ \\
2 \\
2 \\
\hdashline 2
\end{tabular} & $\begin{array}{c}\text { mole/kg of } \\
\text { mixture } \\
0.05_{4} \\
.06_{4} \\
.030\end{array}$ \\
\hline $\begin{array}{r}6 \\
7 \\
8 \\
9 \\
10\end{array}$ & $\begin{array}{l}650.60 \\
220.23 \\
230.26 \\
302.33 \\
260.29\end{array}$ & $\begin{array}{l}.4 \\
.5 \\
.4 \\
.4 \\
.4\end{array}$ & $\begin{array}{l}.006 \\
.02_{3} \\
.01_{7} \\
.01_{3} \\
.01_{5}\end{array}$ & $\begin{array}{l}2 \\
2.5 \\
2 \\
2 \\
2\end{array}$ & $\begin{array}{l}.030 \\
.1_{1} \\
.08_{5} \\
.06_{5} \\
.07_{5}\end{array}$ \\
\hline $\begin{array}{l}11 \\
12 \\
13 \\
14 \\
15\end{array}$ & $\begin{array}{l}260.29 \\
190.20 \\
220.23 \\
220.23 \\
240.14\end{array}$ & $\begin{array}{l}.4 \\
.6 \\
.4 \\
.4 \\
.4\end{array}$ & $\begin{array}{l}.01_{5} \\
.03_{1} \\
.01_{8} \\
.01_{8} \\
.01_{7}\end{array}$ & $\begin{array}{l}2 \\
1 \\
2 \\
2 \\
2\end{array}$ & $\begin{array}{l}.07_{5} \\
.05_{2} \\
.08_{9} \\
.08_{9} \\
.08_{2}\end{array}$ \\
\hline $\begin{array}{l}16 \\
17 \\
18 \\
19 \\
20\end{array}$ & $\begin{array}{r}\text { a } 310.89 \\
\text { a } 271.26 \\
230.26 \\
260.29 \\
216.20\end{array}$ & $\begin{array}{l}.4 \\
.4 \\
1^{.4} \\
0.4 \\
.4\end{array}$ & $\begin{array}{l}.01_{3} \\
.01_{5} \\
.04_{3} \\
.01_{5} \\
.01_{8}\end{array}$ & $\begin{array}{l}3 \\
2 \\
2 \\
2 \\
2\end{array}$ & $\begin{array}{l}\text { a. } 09_{4} \\
.07_{2} \\
.08_{5} \\
.075 \\
.09_{1}\end{array}$ \\
\hline $\begin{array}{l}21 \\
22 \\
23 \\
24 \\
25\end{array}$ & $\begin{array}{l}216.20 \\
190.20 \\
260.29 \\
258.27 \\
190.20\end{array}$ & $\begin{array}{l}.4 \\
3.5 \\
0.4 \\
1 \\
0.8\end{array}$. & $\begin{array}{l}.01_{8} \\
.17_{8} \\
.01_{5} \\
.03_{8} \\
.04_{2}\end{array}$ & $\begin{array}{l}2 \\
4 \\
2 \\
2 \\
4\end{array}$ & $\begin{array}{l}.09_{1} \\
.20 \\
.07_{5} \\
.07_{6} \\
.20\end{array}$ \\
\hline $\begin{array}{l}26 \\
27 \\
28\end{array}$ & $\begin{array}{l}260.29 \\
312.37 \\
262.31\end{array}$ & $\begin{array}{l}1^{.4} \\
0.4\end{array}$ & $\begin{array}{l}.01_{5} \\
.03_{2} \\
.01_{5}\end{array}$ & $\begin{array}{l}2 \\
3 \\
2\end{array}$ & $\begin{array}{l}.075 \\
.09_{3} \\
.07_{5}\end{array}$ \\
\hline
\end{tabular}

a Equivalent weight.

\subsection{Measurement of Infrared Absorption}

The spectrograms are shown in figures 2 and 3. Those in the 2 - to $15-\mu$ range for compounds 7,12 , $18,22,24,25$, and 27 were recorded with a Beckman Model IR4 (double-beam) spectrophotometer equipped with prisms of sodium chloride; they have deliberately been reproduced somewhat differently from 

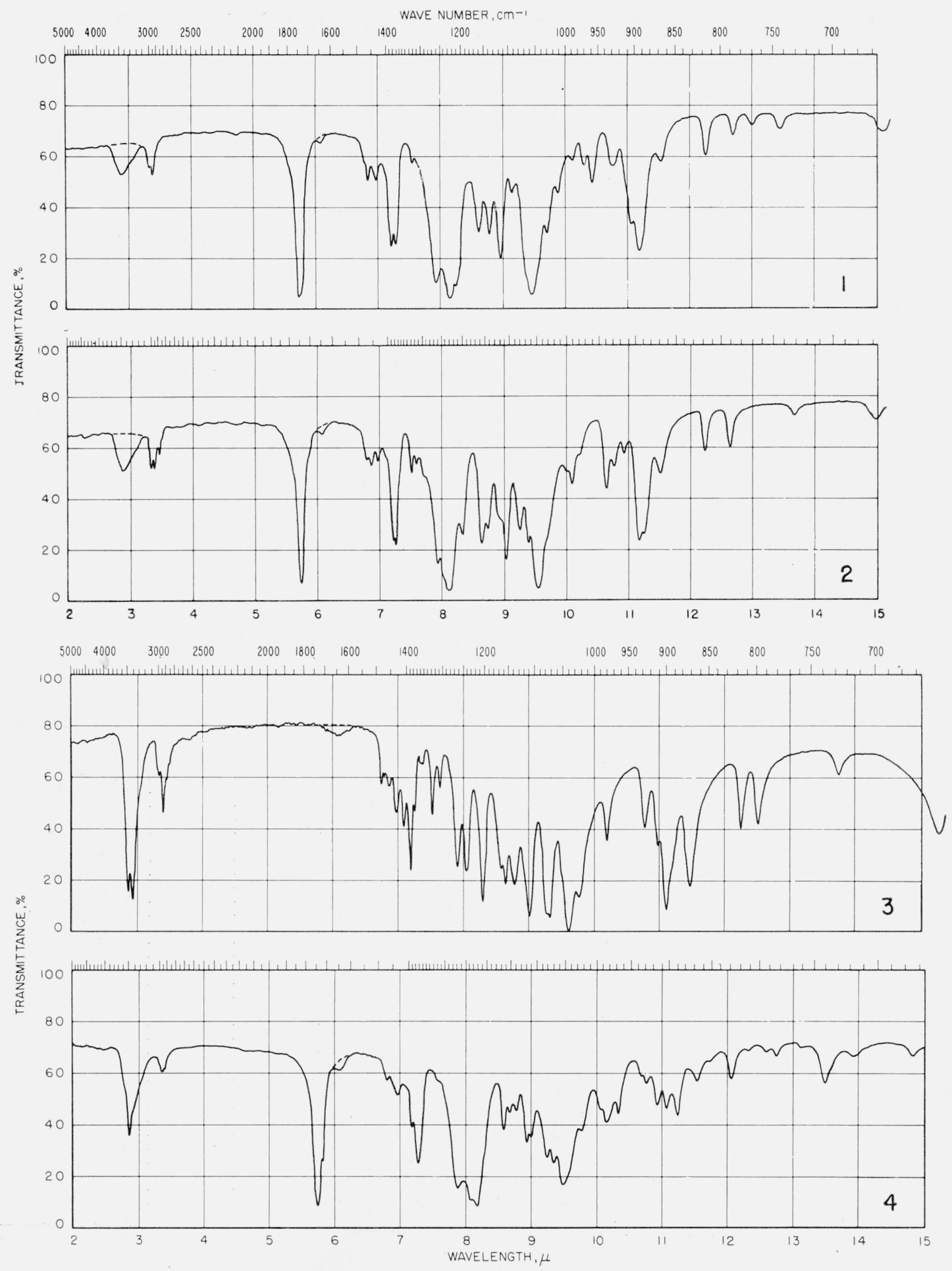

FIGURE 2. Spectograms of materials in petassium chloride pellets.

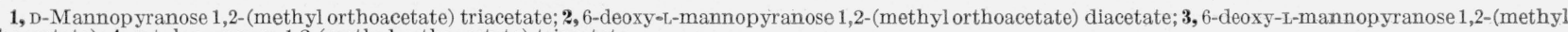
orthoacetate); 4, D-talopyranose 1,2-(methyl orthoacetate) triacetate. 

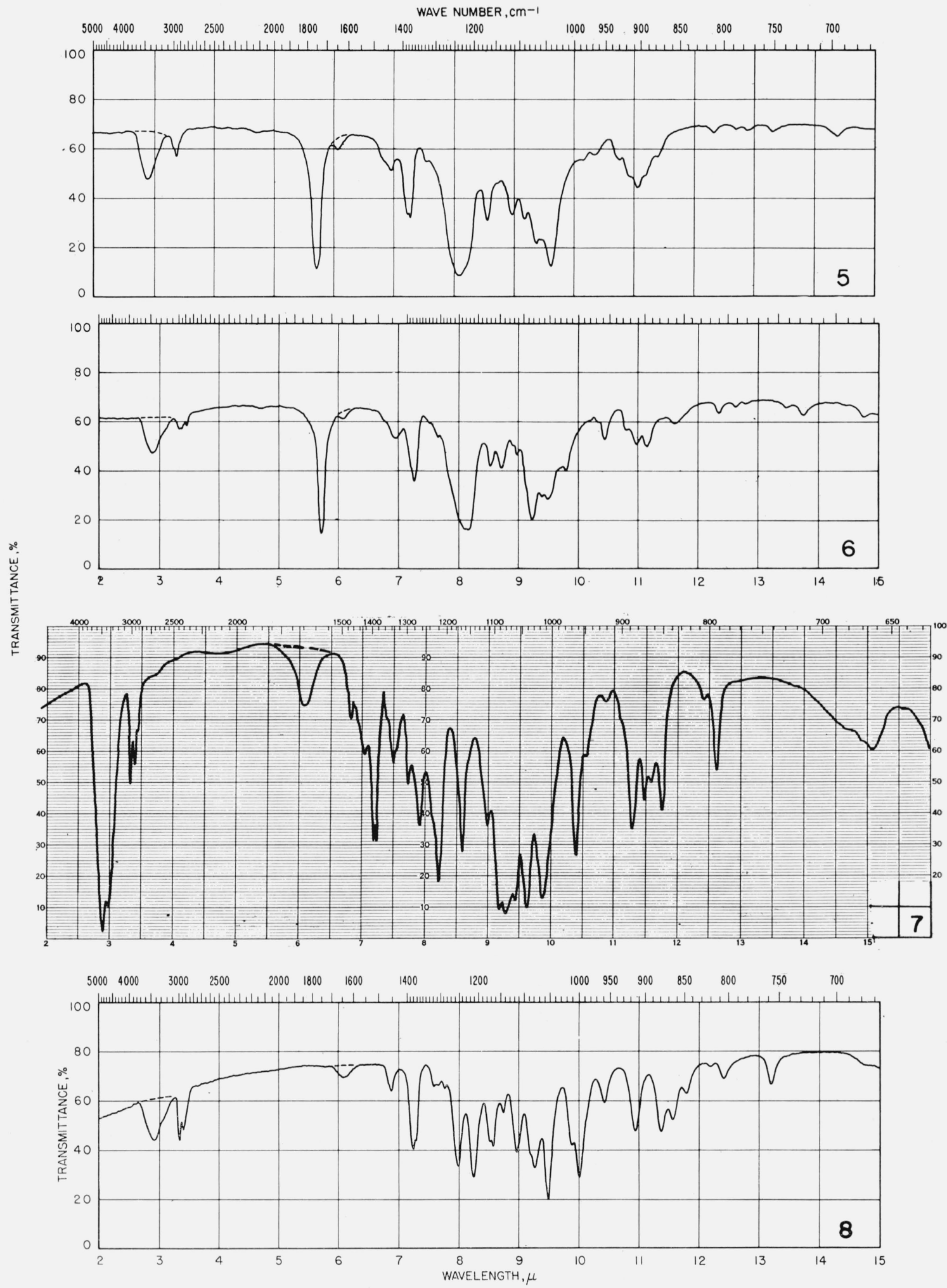

Figure 2. Spectograms of materials in potassium chloride pellets. - Continued

5, $\beta$-D-glucopyranosyl-(1 $\rightarrow 4$ )-D-mannopyranose 1,2-(methyl orthoacetate) hexaacetate; $\mathbf{6}, \boldsymbol{\beta}$-D-galactopyranosyl-(1 $\rightarrow 4$ )-D-altropyranose 1,2 -(methyl orthoacetate) hexaacetate; $\boldsymbol{\gamma}, 1,2$-O-isopropylidene-D-galactopyranose; 8, 1,2:3,4-di- $O$-isopropylidene-L-arabinopyranose. 

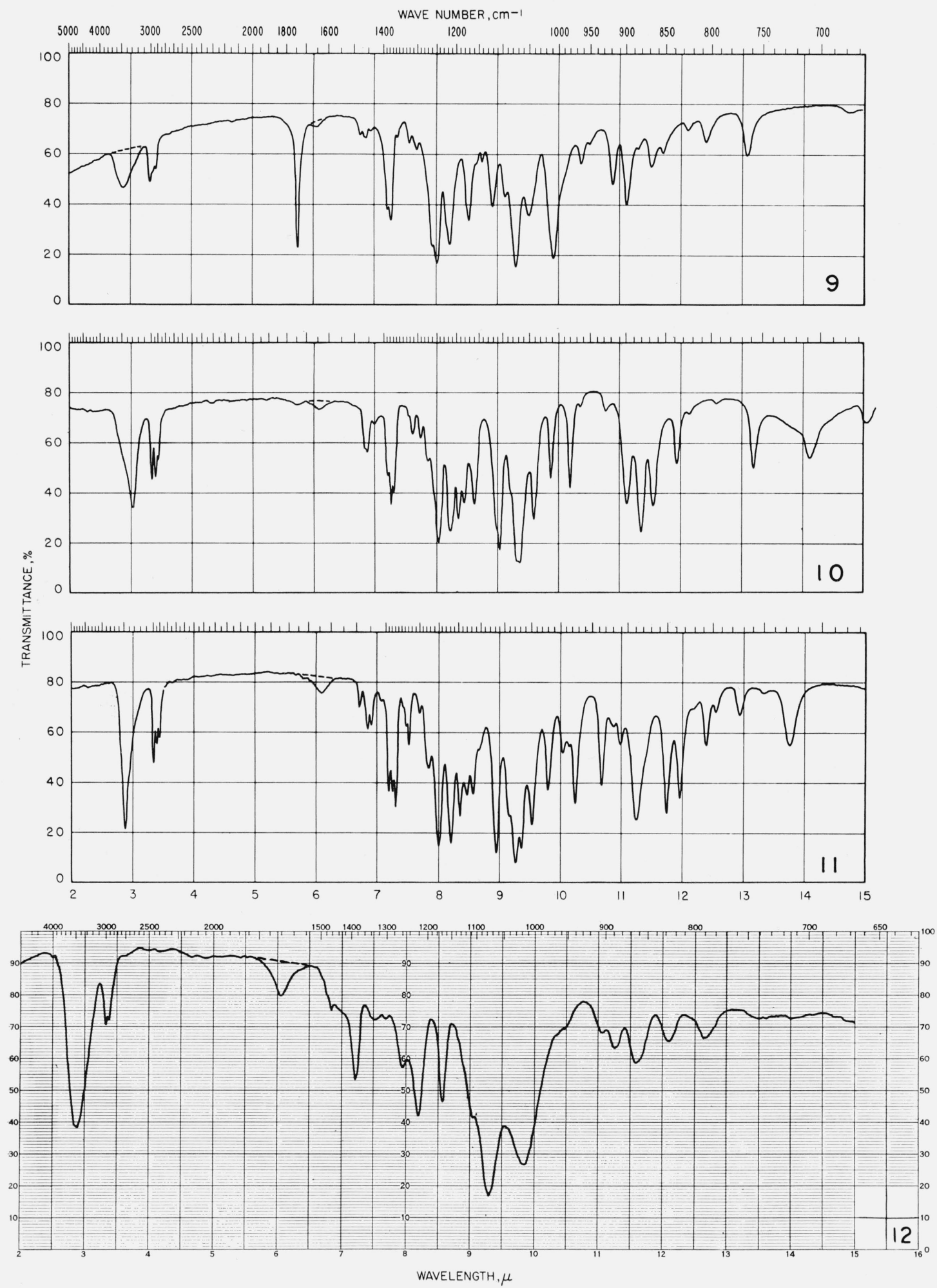

FiguRE 2. Spectograms of materials in potassium chloride pellets. - Continued

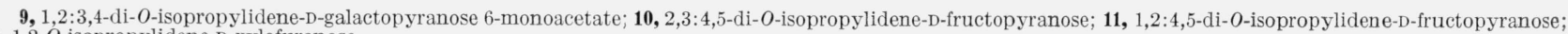
12, 1,2-O-isopropylidene-D-xylofuranose. 

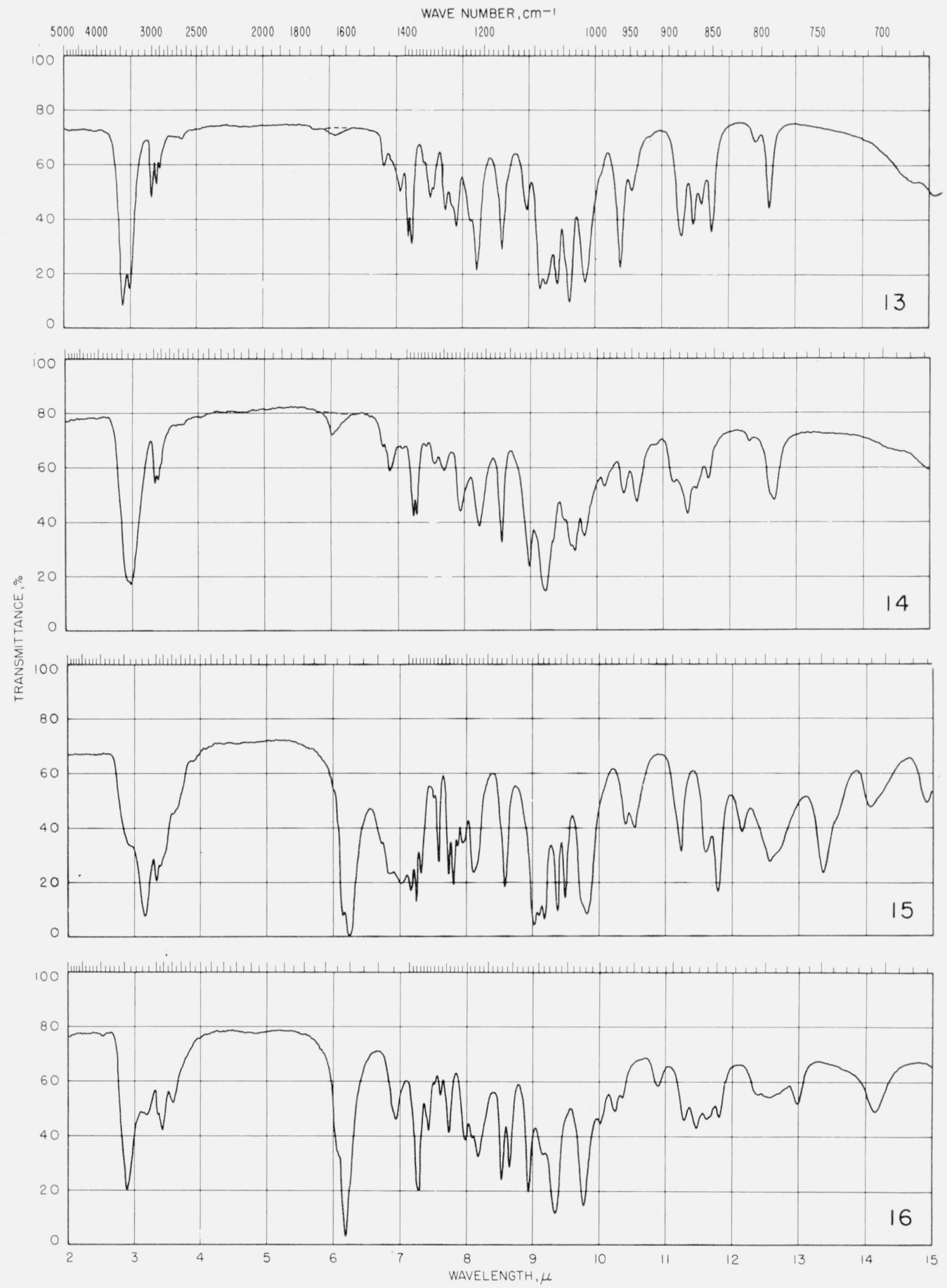

Figure 2. Spectograms of materials in potassium chloride pellets. - Continued

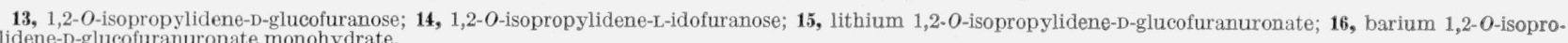
pylidene-D-glucofuranuronate monohydrate. 

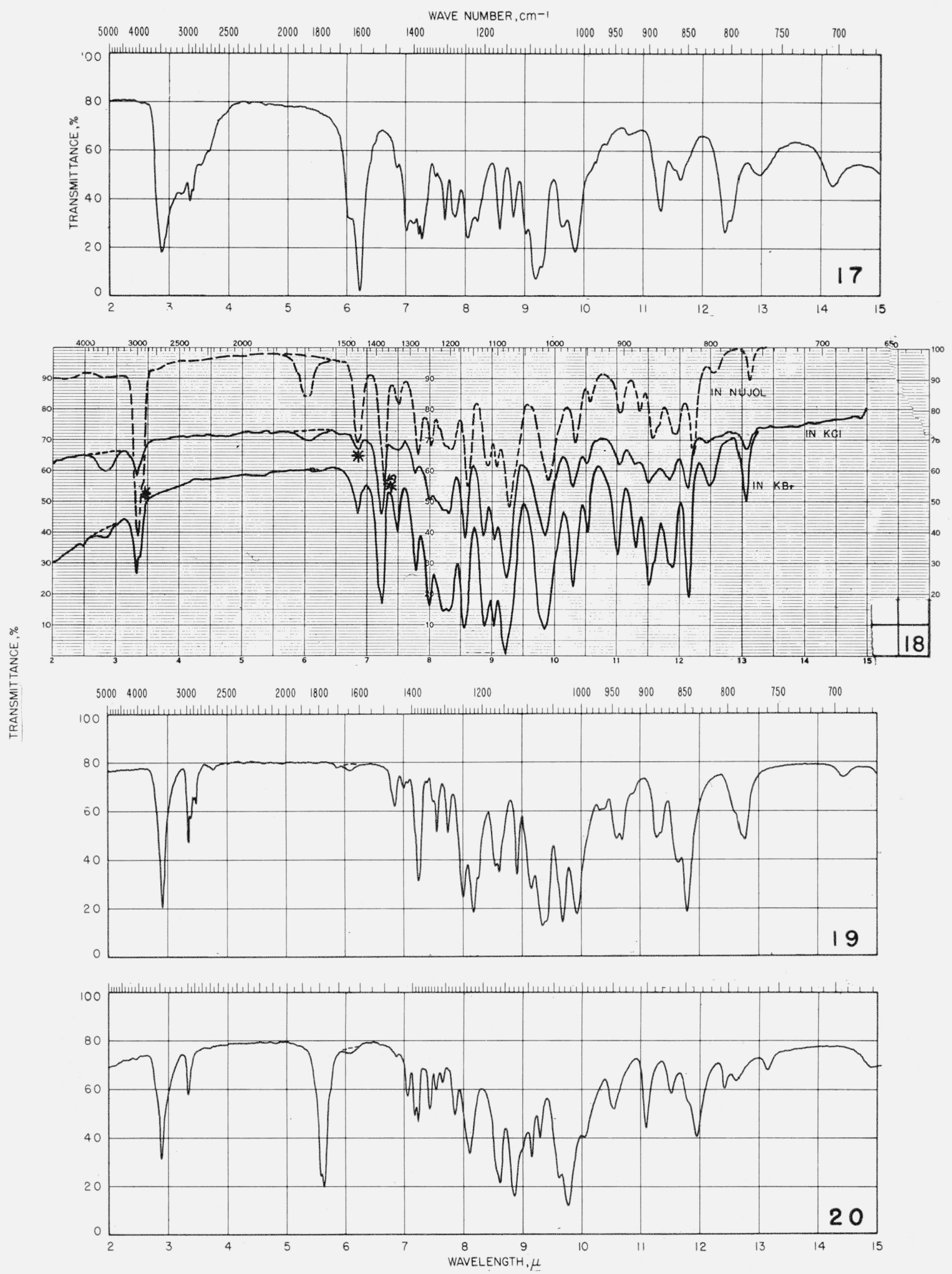

FIGURE 2. Spectograms of materials in potassium chloride pellets.-Continued

17, calcium 1,2-O-isopropylidene-L-idofuranuronate dihydrate; 18, 1,2:3,5-di- $O$-isopropylidene-D-xylofuranose; 19, 1,2:5,6-di- $O$-isopropylidene-D-glucofuranose; 20, 1,2-O-isopropylidene-D-glucofuranurono-6,3-lactone, 

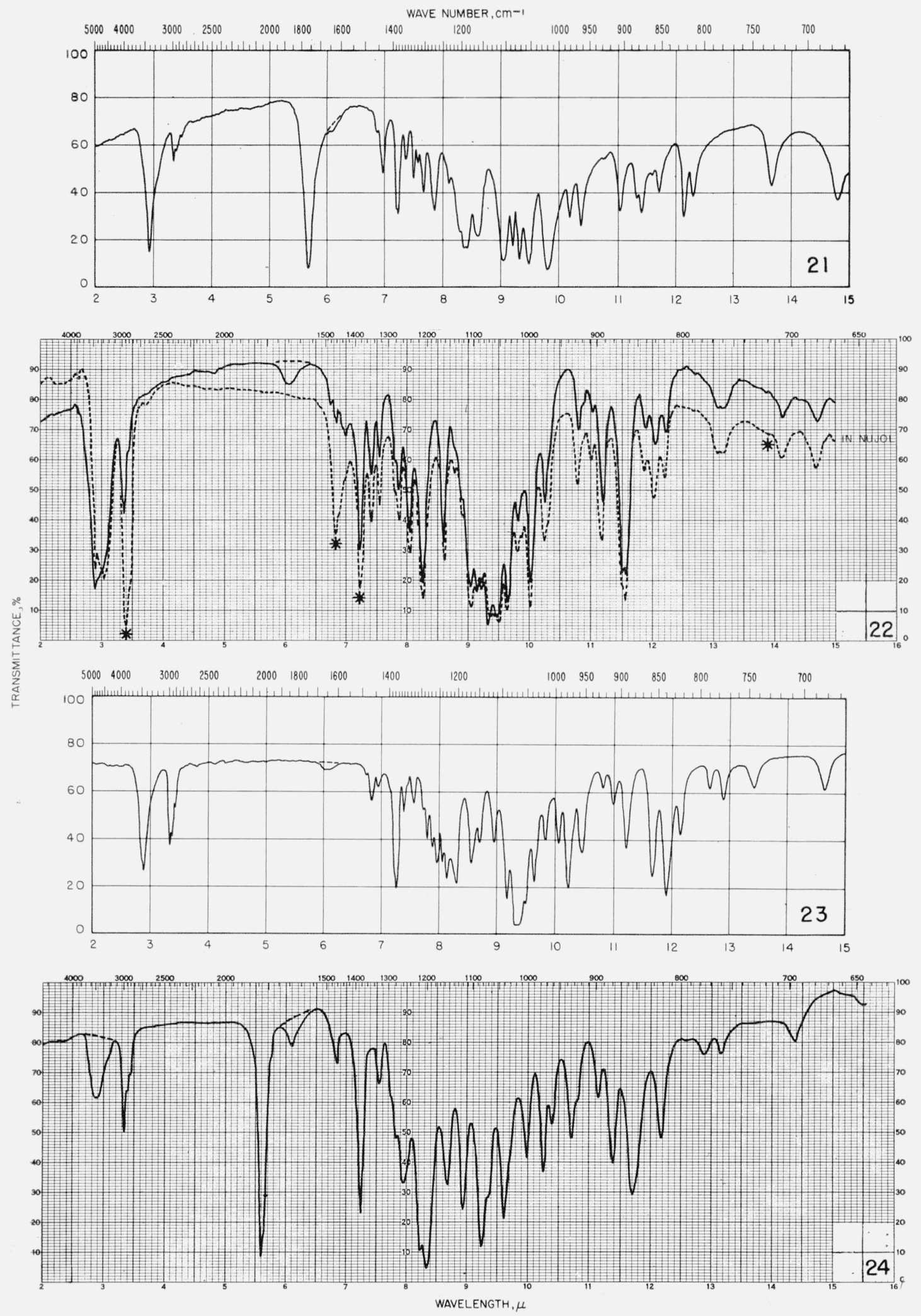

Figure 2. Spectograms of materials in potassium chloride pellets.-Continued

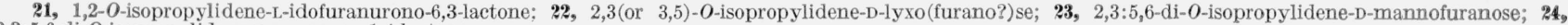
2,3:5,6-di- $O$-isopropylidene-D-mannono-1,4-lactone. 

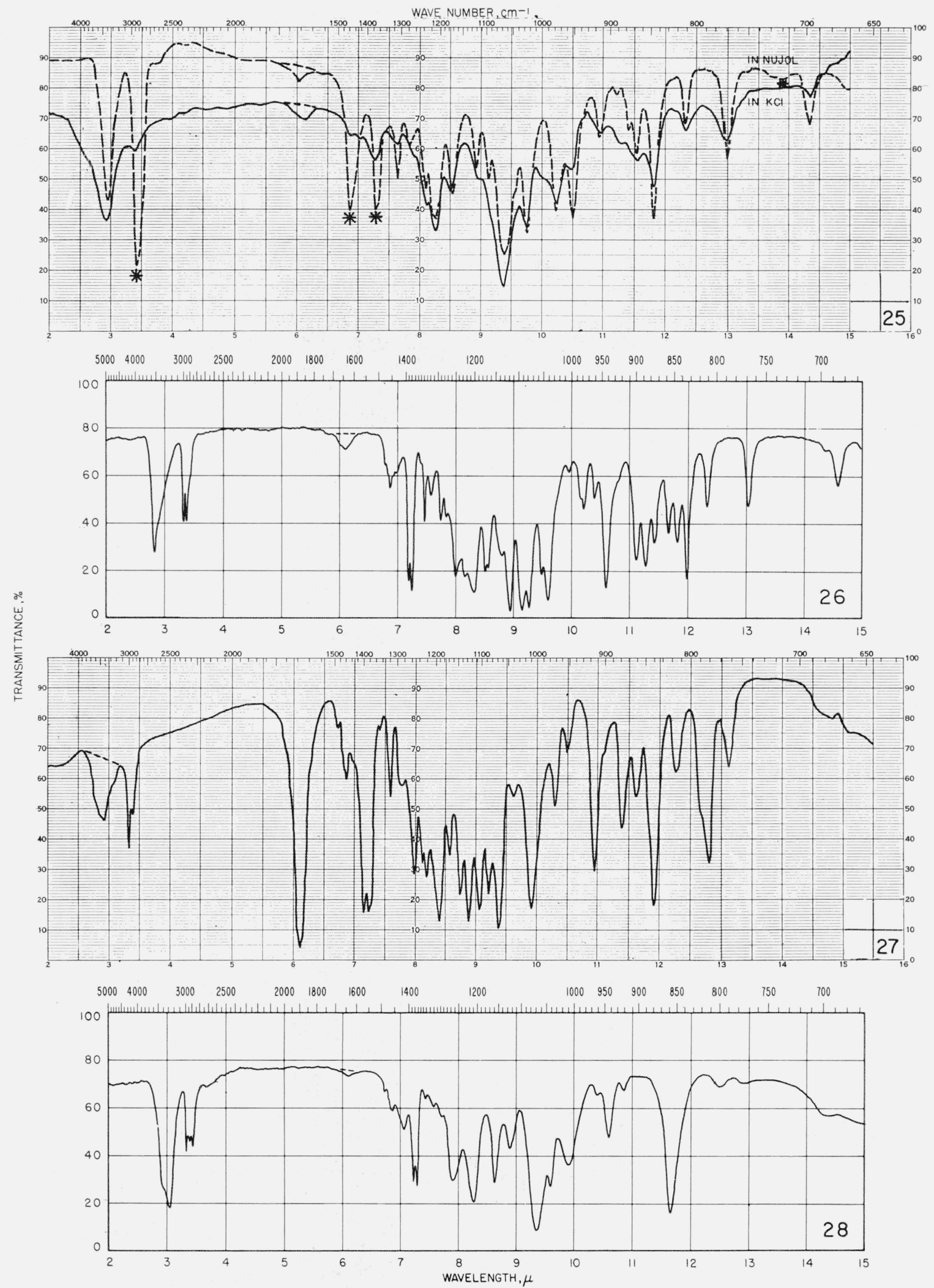

FIGURE 2. Spectograms of materials in potassium chloride pellets.-Continued 

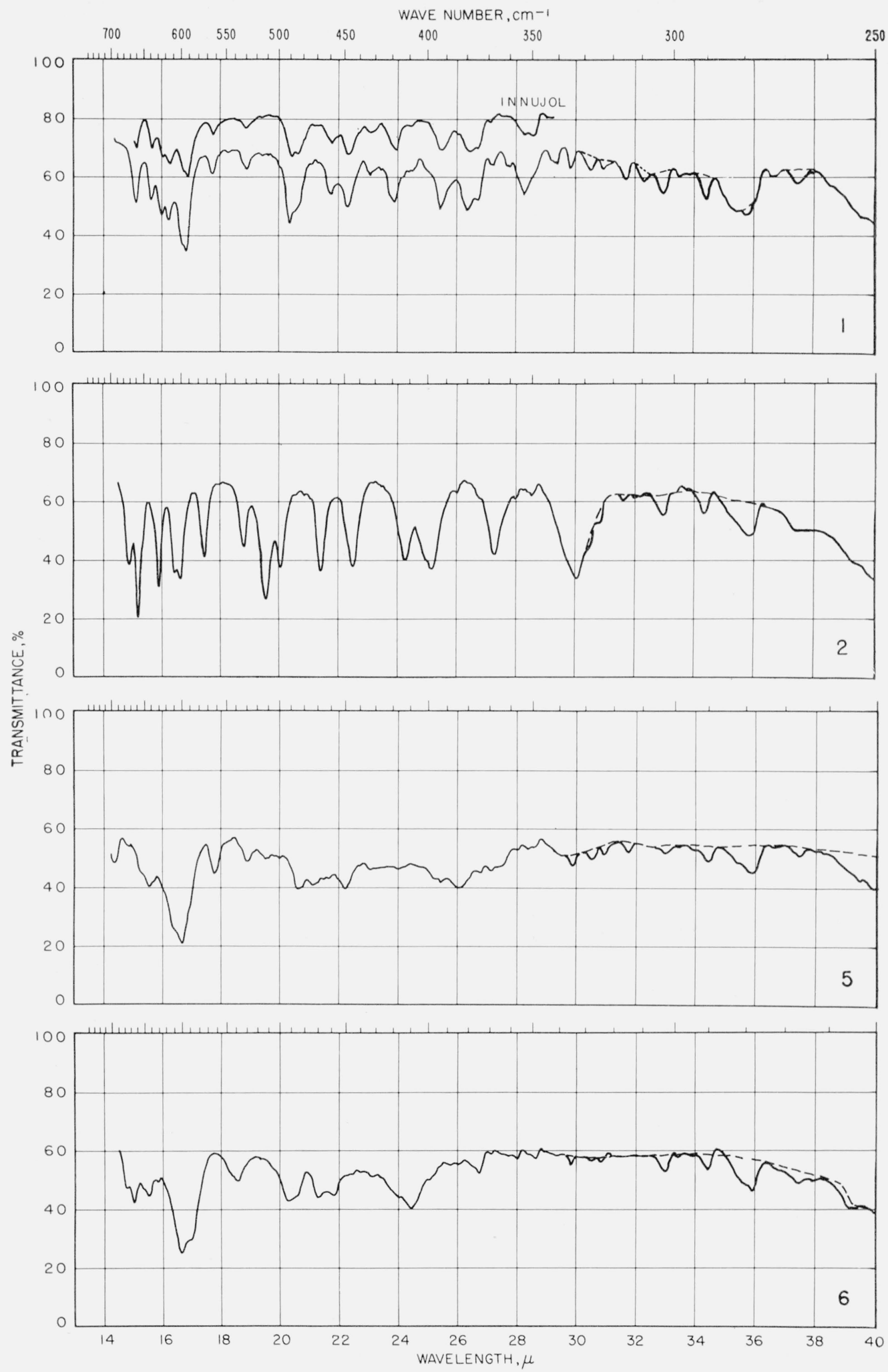

Figure 3. Spectograms of materials in potassium iodide pellets.

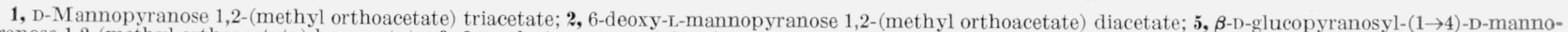
pyranose 1,2 -(methyl orthoacetate) hexaacetate; $\mathbf{6}, \boldsymbol{\beta}$-D-galactopyranosyl-( $1 \rightarrow 4$ )-D-altropyranose 1,2 -(methyl orthoacetate) hexaacetate. 

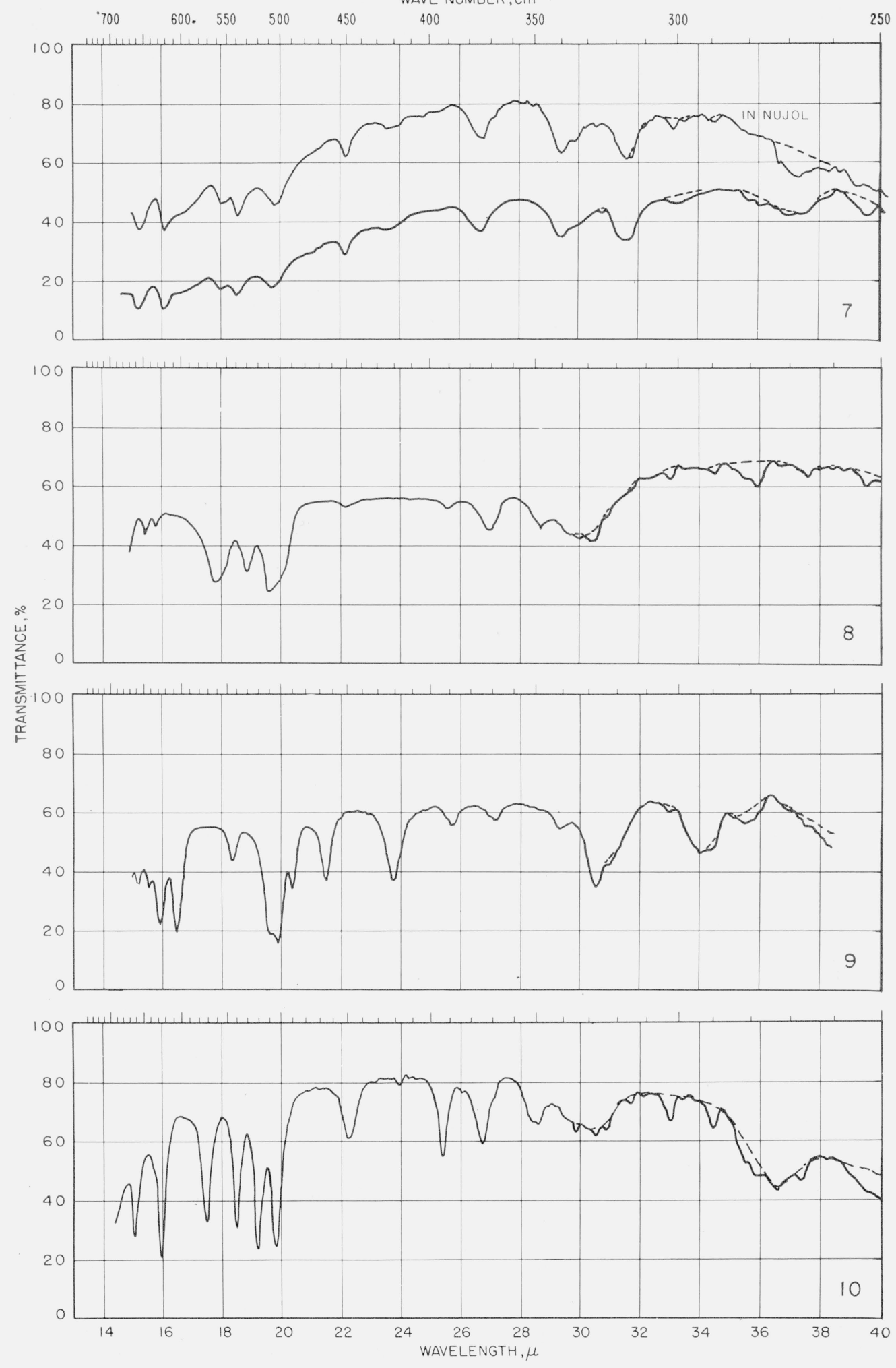

Figure 3. Spectograms of materials in potassium iodide pellets.-Continued

7, 1,2-O-isopropylidene-D-galactopyranose; 8, 1,2:3,4-di- $O$-isopropylidene-L-arabinopyranose; 9 , 1,2:3,4-di- $O$-isopropylidene-D-galactopyranose 6 -monoacetate; 10, 2,3:4,5-di-O-isopropylidene-D-fructopyranose. 

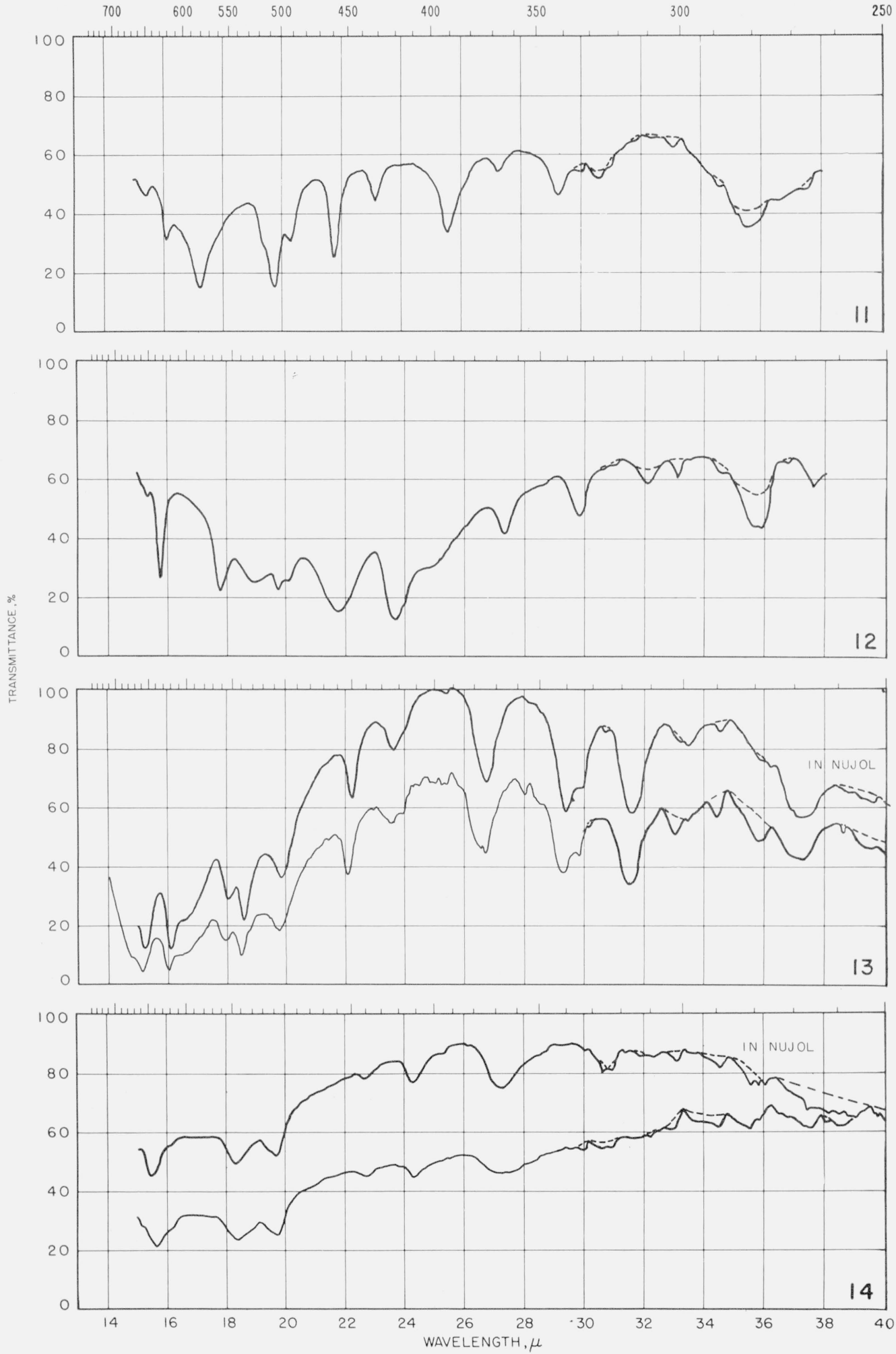

Figure 3. Spectograms of materials in potassium iodide pellets. - Continued

11, 1,2:4,5-di-O-isopropylidene-D-fructopyranose; 12, 1,2-O-isopropylidene-D-xylofuranose; 13, 1,2-O-isopropylidene-D-glucofuranose; 14, 1,2-O-isopropylidene-Lidofuranose. 

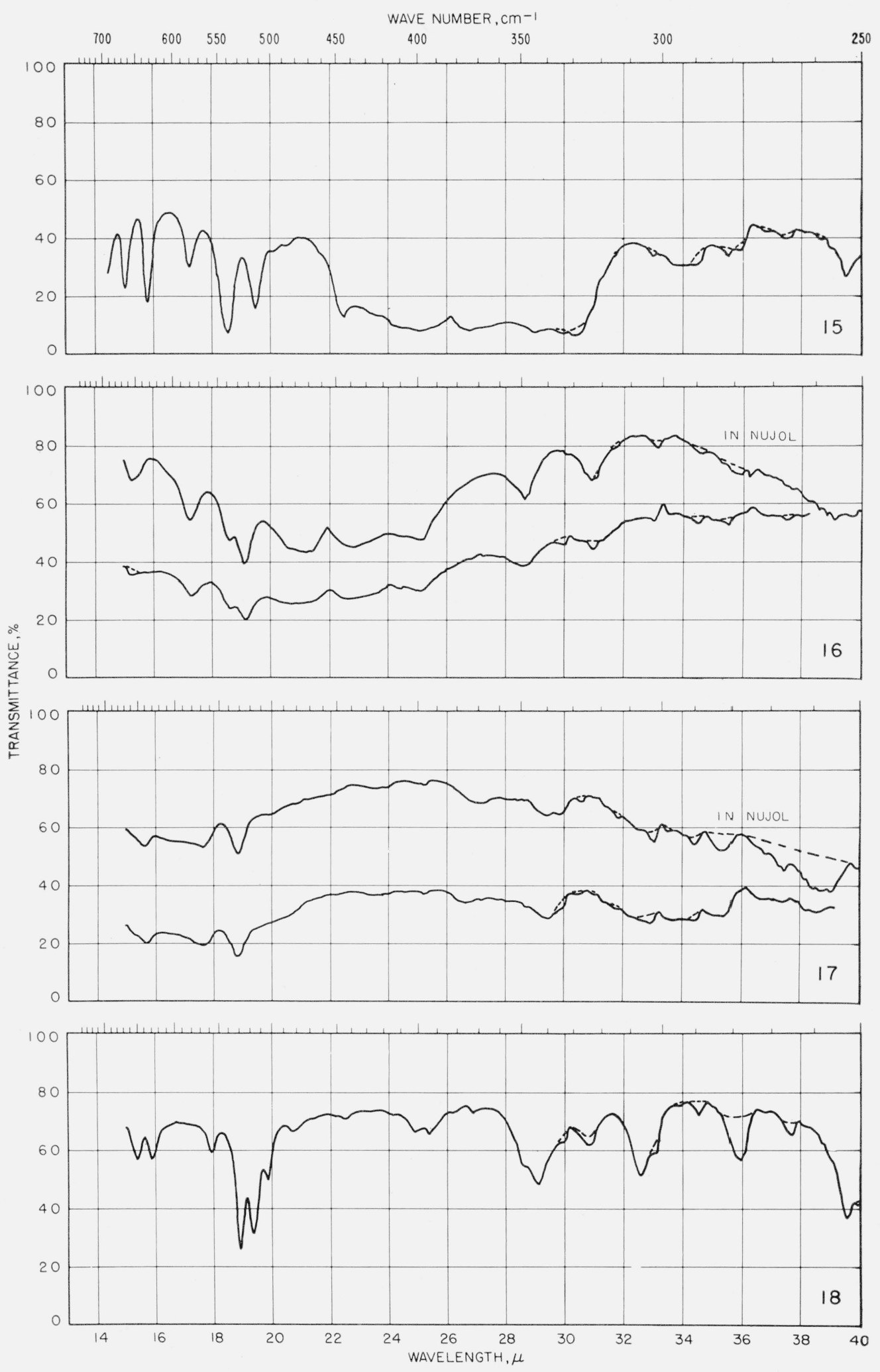

Frgure 3. Spectograms of materials in potassium iodide pellets.-Continued

15, Lithium 1,2-O-isopropylidene-D-glucofuranuronate; 16, barium 1,2-O-isopropylidene-D-glucofuranuronate monohydrate; 17, calcium 1,2-O-isopropylidene-Lidofuranuronate dihydrate; 18, 1,2:3,5-di-O-isopropylidene-D-xylofuranose. 

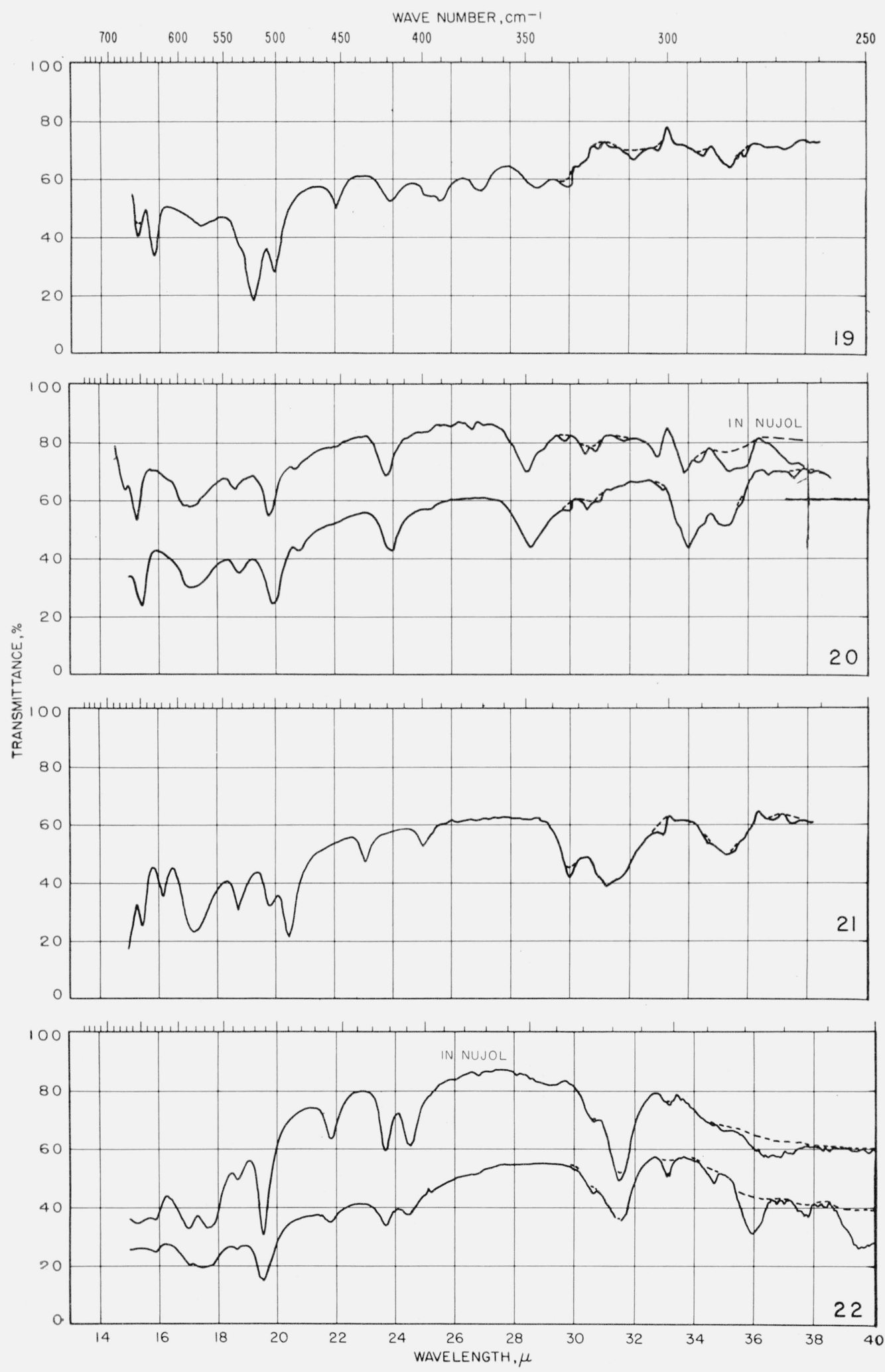

FIGURE 3. Spectograms of materials in potassium iodide pellets.-Continued

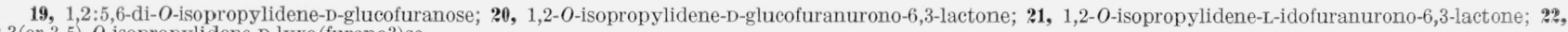
2,3 (or 3,5)-O-isopropylidene-D-lyxo (furano?) se. 

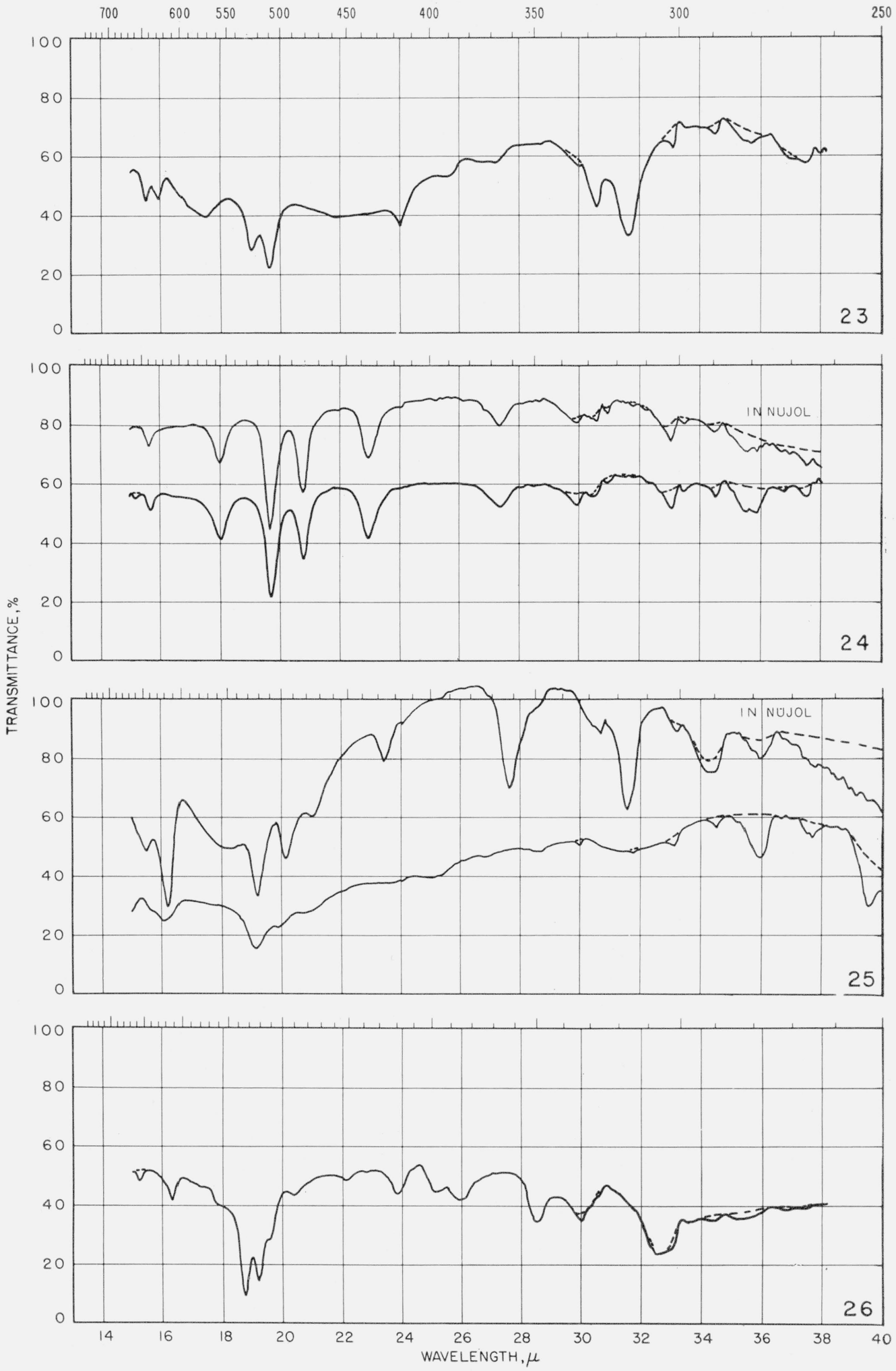

Figure 3. Spectograms of materials in potassium iodide pellets.-Continued

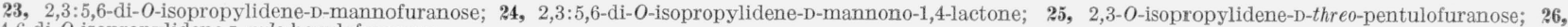
2,3:4,6-di- 0 -isopropylidene-L- $x y l 0$-hexulofuranose. 


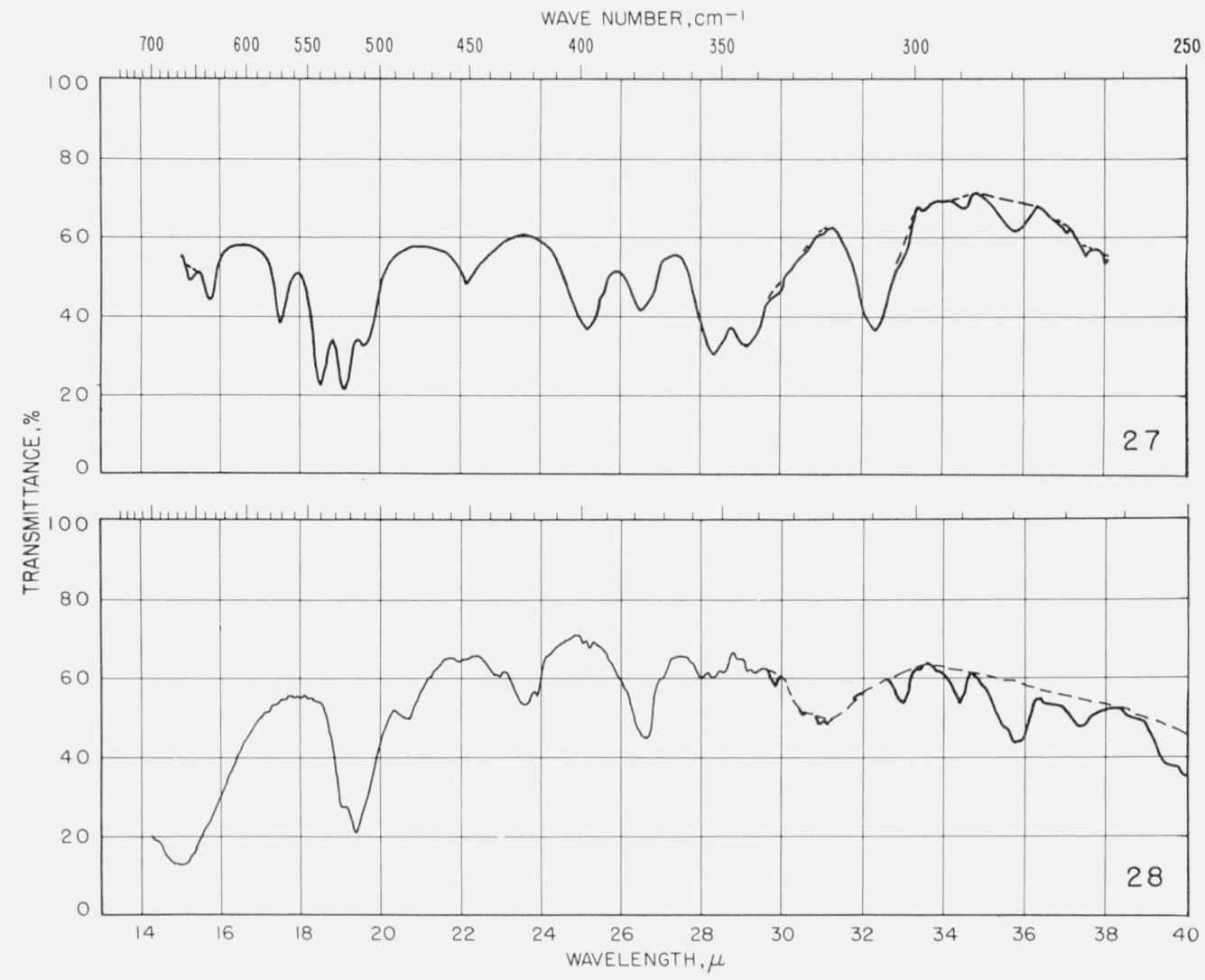

FIGURE 3. Spectograms of materials in potassium iodide pellets.-Continued

27, Potassium 2,3:4,6-di-O-isopropylidene-L-xylo-hexulofuranonate; 28, 1,2:5,6-di- $O$-isopropylidene-D-mannitol.

the rest of the spectra. All the other spectrograms were recorded with a Perkin-Elmer Model 21 (doublebeam) spectrophotometer equipped with a prism of sodium chloride (for the $2-$ to $15-\mu$ range) and of cesium bromide (for the 15 - to $40-\mu$ range). The use of these two prisms was found to be adequate for obtaining survey or identification spectra encompassing the entire 2 - to $40-\mu$ range, because we have found that the resolution obtainable with a cesium bromide prism is not much inferior to that given by a potassium bromide prism in the 15 - to $20-\mu$ range and is about its equal in the 20- to $25-\mu$ range. By replacing the usual, stray-radiation filter-turret with one containing retractable filters (Reststrahlen mirrors) of lithium fluoride (for the 15 - to $30-\mu$ region) and of calcium fluoride (for the $30-$ to $40-\mu$ region), the stray radiation (encountered in the 15- to $40-\mu$ region when a prism of cesium bromide is used) was virtually eliminated for the 15 - to $34-\mu$ range, and reduced to one percent at $36.5 \mu$ and to two percent at $38 \mu$. No pellet blank was inserted and, indeed, this is not at present practical for the far infrared, because insufficient energy is available for that region.

In the presence of stray radiation, it is not in general possible to achieve complete compensation for substances, such as water vapor, common to the reference and sample beams of the spectrophotometer. The spectra were recorded without compensation (in the reference beam) for reflection or scatter by the pellet, or for absorption by traces of moisture in the sugar derivative or in the alkali-metal halide. Con- sequently, in the 2 - to 15 - $\mu$ range, a small amount of absorption attributable to water was observed at 2.9 and $6.1 \mu$. Attention is drawn to these regions by means of dashed lines.

Similarly, some uncompensated absorption by atmospheric water vapor was evident in the far-infrared curves, and the spectral region beyond about $34 \mu$ was doubtful in the sense that weak bands might not be observed because of the superimposed (uncompensated) bands due to water. Hence, these regions are drawn on the spectrograms with dashed lines, inserted after consideration of the curves (shown in fig. 4) obtained for potassium iodide, moist potassium iodide, and Nujol. These dashed lines are merely precautionary; they should not be interpreted quantitatively.

In the 2- to $15-\mu$ range, the accuracy of the wavelength readings was better than $\pm 0.02 \mu$; in the 15 to $40 \mu$ range, the accuracy was within $\pm 0.05 \mu$.

Because of the possibility of interaction of the various compounds with the pelleting halide under high pressure, the spectra of typical compounds were also recorded in a Nujol mull (requiring no pressure) for comparison. On one occasion, compound 20 gave visual (development of color) and spectrographic evidence of interaction with potassium iodide and, to a smaller extent, with potassium bromide, but not with potassium chloride; however, this behavior was not observed on repetition with fresh samples of the halides.

The spectra (2 to $15 \mu$ ) given for compound 18 illustrate how bands exhibited by a compound suspended in potassium chloride can be obscured (by the bands of Nujol) when a Nujol mull is employed. Another reason for preferring the alkali-halide pellets 


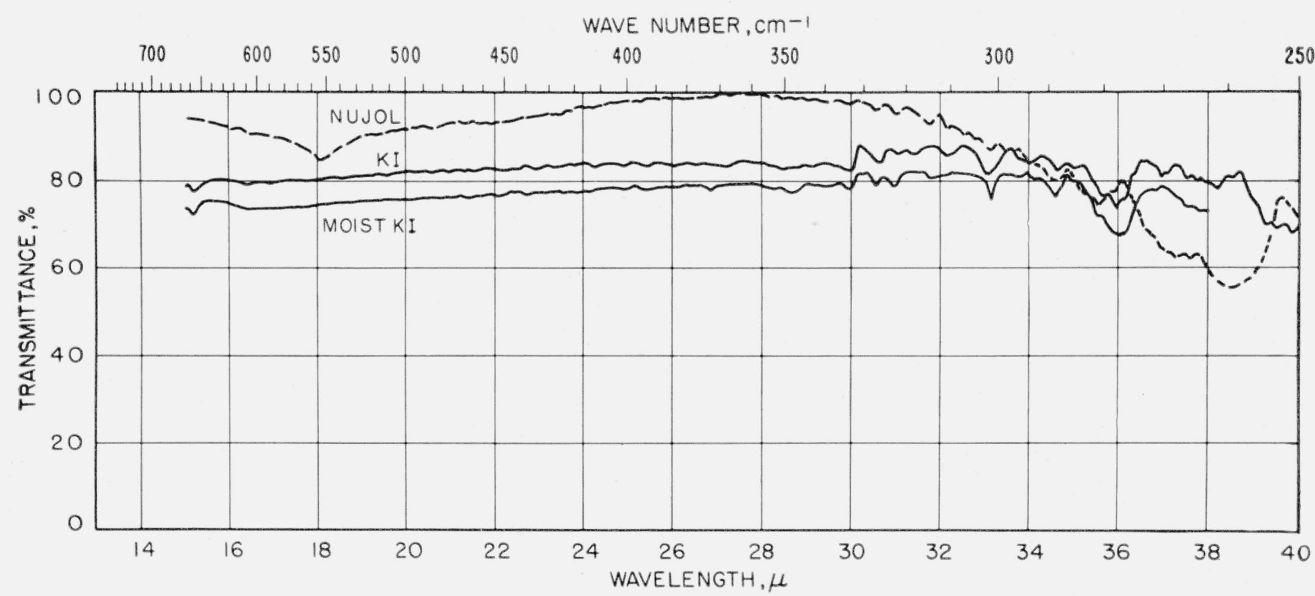

FIgURE 4. Spectograms given by Nujol, potassium iodide pellet, and moist potassium iodide pellet in the region 15 to $40 \mu$.

is that some of the compounds studied are not sufficiently soluble in such solvents as dioxane, carbon disulfide, chloroform, or carbon tetrachloride to afford solutions concentrated enough for recording of satisfactory infrared absorption spectra.

In table 6 are shown the calculated concentrations, in mole per kilogram of alkali-metal halide, of the various pellets. These varied rather widely because of (a) the range in molecular weight of the compounds and (b) the different concentrations (in milligram per milligram of halide) which were found necessary for adequate recording of the spectra. As a consequence, comparisons of intensity of absorption, from one compound to another, can only be true and quantitative where the concentration (in mole per kilogram) is the same. Intercomparisons made for the other compounds are relative and qualitative as regards the intensity of the bands, although the positions of the bands (in microns) may properly be compared.

Insufficient material was available for recording the spectra of compounds 3 and 4 in the 15 - to $40-\mu$ region.

\subsection{Spectra Measured Under Different Conditions}

The infrared absorption spectra of crystalline materials show more bands than the spectra of the same compounds in solution. [This is because, for the solid, the following factors are operative: (1) A removal of degeneracies by perturbations from lattice forces, (2) an intensification of overtones and combination vibrations, and (3) occurrence of combination vibrations between molecular and lattice modes in the solid.]

The spectra (in the 2- to $15-\mu$ region) of compounds 1 and 2 in carbon tetrachloride and in dioxane had been published previously [25]; those given in pellets of potassium chloride for the same region of wavelength are shown in figure 2. A comparison of the relative complexity of the spectra for the solutions and pellets of compounds 1 and 2 (as well as of many other sugar derivatives yet to be published) shows the above-mentioned effect.
The authors express their gratitude to Harriet L. Frush, J. D. Moyer, and R. Schaffer for providing samples of certain of the compounds used in this study; to Alex Cohen for technical assistance; and to J. J. Comeford and F. P. Czech for recording some of the infrared absorption spectra.

\section{References}

[1] H. S. Isbell, J. Research NBS 57, 171 (1956) RP2707.

[2] H. S. Isbell, BS J. Research 7, 1115 (1931) RP392.

[3] W. W. Pigman and H. S. Isbell, J. Research NBS 19, 189 (1937) RP1021.

[4] H. L. Frush and H. S. Isbell, J. Research NBS 27,413 (1941) RP1429.

[5] J. A. Mills, Advances in Carbohydrate Chem. 10, 18 (1955).

[6] H. S. Isbell, Ann. Rev. Biochem. 9, 65 (1940).

[7] V. Boekelheide, L. Liberman, J. Figueras, C. Krespan, F. C. Pennington, and D. S. Tarbell, J. Am. Chem. Soc. 71, 3303 (1949)。

[8] L. P. Kuhn, Anal. Chem. 22, 276 (1950).

[9] L. I. Smith and R. H. Anderson, J. Org. Chem. 16, 972 (1951).

[10] R. H. Anderson, Ph. D. Thesis, University of Minnesota, 1950.

[11] E. D. Bergmann and S. Pinchas, Rec. trav. chim. 71, 161 (1952)

[12] S. A. Barker, E. J. Bourne, and D. H. Whiffen, Methods of Biochem. Anal., vol. 3, p. 219 (Interscience Publishers, Inc., New York, N.Y., 1956).

[13] H. Tschamler and R. Leutner, Monatsh. 83, 1502 (1952).

[14] R. H. Jaeger and H. Smith, J. Chem. Soc. 1955, 160.

[15] S. A. Barker, E. J. Bourne, M. Stacey, and D. H. Whiffen, J. Chem. Soc. 1954, 171.

[16] S. A. Barker, E. J. Bourne, R. Stephens, and D. H. Whiffen, J. Chem. Soc. 1954, 3468.

[17] S. A. Barker and R. Stephens, J. Chem. Soc. 1954, 4550.

[18] O. Svanberg and K. Sjöberg, Ber. deut. chem. Ges. 56, $863(1923)$.

[19] H. Müller and T. Reichstein, Helv. Chim. Acta 21, 251 (1938).

[20] O. Svanberg, Ber. deut. chem. Ges. 56, 2195 (1923).

[21] W. N. Haworth and C. R. Porter, J. Chem. Soc. 1928, 611.

[22] K. Freudenberg, H. Molter, and G. Dietrich, Chem. Ber. 80, $53(1947)$.

[23] P. A. Levene and A. L. Raymond, J. Biol. Chem, 102, 317 (1933).

[24] D. H. Anderson and N. B. Woodall, Anal. Chem. 25, 1906 (1953).

[25] H. S. Isbell, F. A. Smith, E. C. Creitz, H. L. Frush, J. D. Moyer, and J. E. Stewart, J. Research NBS 59, 41 (1957) RP2772.

Washington, January 29, 1959 